NBER WORKING PAPER SERIES

\title{
BANKS, MARKET ORGANIZATION, AND MACROECONOMIC PERFORMANCE: AN AGENT-BASED COMPUTATIONAL ANALYSIS
}

\author{
Quamrul Ashraf \\ Boris Gershman \\ Peter Howitt \\ Working Paper 17102 \\ http://www.nber.org/papers/w17102 \\ NATIONAL BUREAU OF ECONOMIC RESEARCH \\ 1050 Massachusetts Avenue \\ Cambridge, MA 02138 \\ June 2011
}

The authors are grateful for suggestions from Blake LeBaron, Ned Phelps, Bob Tetlow, and various seminar participants at the Federal Reserve Bank of Cleveland, the Marschak Colloquium at UCLA, the Center on Capitalism and Society at Columbia, Brandeis University, Columbia Business School, the Federal Reserve Bank of Dallas, the National Bank of Austria, Brown, and MIT, none of whom bears any responsibility for errors or should be taken to endorse the analysis. The research was supported by an NSF grant. The C+t code for the computational model is available for download at http:!//www.econ.brown.eduffac/Peter_Howittworking/BankFail.zip. It was compiled and run as a 32 bit Windows application. The views expressed herein are those of the authors and do not necessarily reflect the views of the National Bureau of Economic Research.

NBER working papers are circulated for discussion and comment purposes. They have not been peerreviewed or been subject to the review by the NBER Board of Directors that accompanies official NBER publications.

(C) 2011 by Quamrul Ashraf, Boris Gershman, and Peter Howitt. All rights reserved. Short sections of text, not to exceed two paragraphs, may be quoted without explicit permission provided that full credit, including $\odot$ notice, is given to the source. 
Banks, Market Organization, and Macroeconomic Performance: An Agent-Based Computational Analysis

Quamrul Ashraf, Boris Gershman, and Peter Howitt

NBER Working Paper No. 17102

June 2011

JEL No. C63,E0,E44,G20,G28

\begin{abstract}
This paper is an exploratory analysis of the role that banks play in supporting the mechanism of exchange. It considers a model economy in which exchange activities are facilitated and coordinated by a self-organizing network of entrepreneurial trading firms. Collectively, these firms play the part of the Walrasian auctioneer, matching buyers with sellers and helping the economy to approximate equilibrium prices that no individual is able to calculate. Banks affect macroeconomic performance in this economy because their lending activities facilitate entry of trading firms and also influence their exit decisions. Both entry and exit have conflicting effects on performance, and we resort to computational analysis to understand how they are resolved. Our analysis sheds new light on the conflict between micro-prudential bank regulation and macroeconomic stability. Specifically, it draws an important distinction between "normal" performance of the economy and "worst-case" scenarios, and shows that micro prudence conflicts with macro stability only in bad times. The analysis also shows that banks provide a "financial stabilizer" that in some respects can more than counteract the more familiar financial accelerator.
\end{abstract}

Quamrul Ashraf

Williams College

Department of Economics

24 Hopkins Hall Drive

Williamstown, MA 01267

Quamrul.H.Ashraf@williams.edu

Boris Gershman

Brown University

Department of Economics

64 Waterman St

Providence, RI 02912

boris_gershman@brown.edu
Peter Howitt

Department of Economics

Brown University, Box B

Providence, RI 02912

and NBER

peter_howitt@brown.edu 


\section{Introduction}

How do banks affect the macroeconomy? If banks get in trouble, how does that matter for various performance measures? In this paper, we develop an agent-based computational model and apply it to explore one possible channel through which banks might affect the macroeconomy, namely their role in what Jevons called the "mechanism of exchange."

In any but the most primitive economic system, exchange activities are organized and coordinated by a network of specialist trading enterprises such as retailers, wholesalers, brokers, and various other intermediaries. These enterprises provide facilities for buying and selling at publicly known times and places, provide implicit guarantees of quality and availability of spare parts and advice, quote and advertise prices, and hold inventories that provide some assurance to others that they can buy at times of their own choosing. In short, this network of intermediaries constitutes the economy's operating system, playing the role in real time that general equilibrium theory assumes is costlessly played in metatime by "the auctioneer," namely that of matching buyers with sellers and helping the economy to approximate the equilibrium vector of prices that no single person is able to calculate. Moreover, unlike the auctioneer, they provide the facilities and the buffer stocks that allow trading to proceed even when the system is far from equilibrium.

The importance of this network of trading enterprises is attested to by Wallis and North (1986), who argue that providing transaction services is the major activity of business firms in the U.S. economy; more specifically, Wallis and North estimated that over half of measured GDP in the U.S. economy consists of resources used up in the transaction process. And indeed, as everyday experience of any household will verify, almost all transactions in a modern economy are conducted with at least one side of the transaction being an enterprise that specializes in making similar transactions.

Banks and other financial intermediaries play a critical role in an economy's trading network, not just because they themselves are part of the network, intermediating between surplus and deficit units, but also because their lending activities influence the entry and exit of other intermediaries throughout the network. Entry of new facilities is neither free nor automatic. It requires entrepreneurship, which is not available in unlimited supply and which frequently needs finance. Likewise, exit of existing facilities constitutes a loss of organizational capital that affects the system's performance, and exit activity is typically triggered by banks deciding when to cut off finance from a failing enterprise.

The purpose of this paper is to present a model that portrays this role of banks in helping the economy to track a coordinated state of general equilibrium. In a sense, our work is a continuation of a line of research into disequilibrium macroeconomics that began with Patinkin (1956, ch. 13) and Clower (1965), and reached its pinnacle in the Barro-Grossman (1976) book, which attempted to flesh out the details of what happens when people trade at prices that make their plans mutually incompatible. That line of research ran into the problem that trading out of equilibrium in one market generates rationing constraints that affect traders in other markets in complicated ways 
that are hard to analyze. Because of these complications, analysis of general disequilibrium became highly intractable, as did the optimization problems facing people. To deal with these complexities, we have chosen to model the mechanism of exchange using the methodology of agent-based computational analysis.

As described by Tesfatsion (2006), agent-based computational economics is a set of techniques for studying a complex, adaptive system involving many interacting agents with exogenously given behavioral rules. ${ }^{1}$ The idea motivating the approach is that complex systems, like economies or anthills, can exhibit behavioral patterns beyond what any of the individual agents in the system can comprehend. So, rather than modeling the system as if everyone's actions and beliefs were coordinated in advance, presumably by someone with a clear understanding of how the system works, people are instead assumed to follow simple rules, whose interaction might or might not lead the system to approximate a coordinated equilibrium. The approach is used to explain system behavior by "growing" it in the computer. Once one has devised a computer program that mimics the desired characteristics of the system in question, one can then use the program as a "culture dish" in which to perform experiments.

More specifically, we use a modified version of the model developed by Howitt and Clower (2000) in which an economy's network of trade specialists was shown to be self-organizing and self-regulating. Howitt and Clower show that, starting from an initial situation in which there is no trading network, such a network will often emerge endogenously, and that once it does emerge it will guide the economy to a stationary equilibrium in which almost all the gains from trade are fully realized.

Here we modify the original Howitt-Clower model to allow for durable goods, fiat money, and government bonds, to include an adaptive central bank that follows a Taylor rule with an explicit inflation target and a fiscal authority that adjusts tax rates in response to changes in the ratio of government debt to GDP, and to allow for banks that lend to the trade specialists in order to finance their fixed and working capital. The banks are subject to a number of regulations, such as required capital adequacy ratios and limits on loan-to-value ratios. We calibrate the model to U.S. data and simulate it many times for many periods under different parameter values to see how banks affect macro performance and how performance, in turn, is affected by different dimensions of bank regulation.

The model we present is an important first attempt at introducing banks into an agent-based computational macro model, focusing on their role in the mechanism of exchange. While it is admittedly too stylized to be considered substantive for policy-making purposes, it does produce three results of general methodological interest. First, the model seems to provide a framework for understanding "rare disasters." As we shall see, most of the time the evolving network of trade intermediaries performs reasonably well in counteracting macro shocks and keeping the economy in a neighborhood of full-capacity utilization. But in a small fraction of simulation runs, the economy

\footnotetext{
${ }^{1} \mathrm{~A}$ wide-ranging survey of the literature using this method in economics is provided by the various contributors to Tesfatsion and Judd (2006).
} 
tends to spiral out of control. The model thus exhibits something like what Leijonhufvud (1973) called "corridor effects;" that is, if the system is displaced far enough from equilibrium, its selfregulating mechanisms are liable to break down entirely. This, however, could not happen in a stochastic linear model, where expected impulse responses are qualitatively independent of the size of displacement. The distinction between median results and worst-case results, in terms of the output gap, shows up dramatically in almost all the experiments we perform on the model. We also find that banks have their biggest impact on performance in those rare cases when the system is far from equilibrium.

Our second result is that the way banks and bank regulation affect macroeconomic performance is often in conflict with conventional notions of micro-prudential bank regulation. Specifically, we find that performance in the worst decile of simulation runs of our model is significantly improved if banks are allowed to use higher loan-to-value ratios and are subject to lower capital adequacy ratios.

The third result concerns the overall role of banks in macroeconomic volatility. It is generally accepted that although finance may help to promote long-run growth and development, this longrun benefit comes at a cost of increased short-run volatility. This general notion is embodied in the basic idea of the "financial accelerator" that Williamson (1987), Bernanke and Gertler (1989), Holmstrom and Tirole (1997), Kiyotaki and Moore (1997), and others have shown can amplify the effects of macroeconomic shocks because of the endogenous nature of collateral. But the present model shows that finance, in the form of banks who make collateralized loans to other business firms, also introduces an important "financial stabilizer," which in many respects can be more powerful than the financial accelerator. In particular, when a negative macroeconomic shock is accompanied by firm failures, the presence of banks that can finance a replacement firm and sustain other existing firms will often dampen the effects of the shock by ameliorating or even averting a secondary wave of failures. It turns out that this financial stabilizer is a key to understanding the above-mentioned tradeoff between micro prudence and macro stability.

The next section contains a brief literature review. Section 3 discusses the basic elements of our model. Section 4 describes the protocol by which agents interact in the model, as well as the behavioral rules that we are imputing to its various actors. Section 5 describes the no-shock full-capacity-utilization equilibrium that the system approximates, and discusses the ways in which entry, exit, and bank lending affect this process. Section 6 describes how the model was calibrated. Section 7 analyzes the differences between how the system behaves in normal times and how it behaves when things go wrong. Section 8 describes our main results concerning the role of the banking system in our model and the implications of this role for bank regulation. It also considers the robustness of our results to changes that make risky banks less conducive to macro stability as a consequence of increasing the costs of bank failure. Section 9 reports the results of a sensitivity analysis, and Section 10 concludes. 


\section{Previous literature}

There is a large literature that studies the effects of financial intermediation on long-term growth through its effects on innovation, risk sharing, capital accumulation, the allocation of capital, and the screening and monitoring of investment projects. ${ }^{2}$ But none of these effects seem likely to trigger a collapse of the sort that policy makers have been trying to avert. As mentioned in the previous section, financial accelerators arising from endogenous collateral have been modeled by various authors, and are currently being introduced into New Keynesian DSGE models (e.g., Gertler and Kiyotaki, 2010) with a view to understanding their role in credit crises. As we shall see, there is a financial accelerator at work in the present model, working through the bank-lending channel; the failure of one firm can impose losses on any bank that has lent to the shop, making it more likely that the bank will further restrict its lending to other firms and, thus, making it more likely that other firms will fail. Since failed firms are not immediately replaced, each failure has a negative impact on aggregate GDP, and the above mechanism will tend to amplify this negative impact. However, we find that in worst-case results these effects are more than offset by the above-mentioned financial stabilizer.

Our model thus speaks to the empirical literature on the effects of financial development on stability (e.g., Easterly et al., 2000; Braun and Larrain, 2005; Raddatz, 2006; Loayza and Raddatz, 2007). In particular, our financial stabilizer provides a rationale for the results of Braun and Larrain (2005) and Raddatz (2006) to the effect that financial development tends to reduce macroeconomic volatility.

More generally, our paper adds to the growing literature on agent-based macroeconomic modeling. This literature traces its roots back to the micro-simulation models of Orcutt et al. (1976), Eliasson (1977), and Bennett and Bergmann (1986), which aimed at capturing heterogeneous microeconomic behavioral rules operating in various sectors of an otherwise standard Keynesian macro model. More recently, such authors as Basu et al. (1998), Howitt and Clower (2000), Dosi et al. (2006), Howitt (2006), Deissenberg et al. (2008), Delli Gatti et al. (2008), Ashraf and Howitt (2008), and Cincotti et al. (2010) have moved the literature closer to the ideal of modeling the economy as a system of interacting "autonomous" agents, that is, agents capable of behavior in an unknown environment. ${ }^{3}$ What distinguishes our approach to agent-based analysis from others is mainly our focus on the self-organizing capabilities of the system of markets through which agents interact. In our model, shocks are intermediated by agents that spontaneously open new markets, while the same shocks are also capable of disrupting markets by inducing or forcing such agents to close their operations.

\footnotetext{
${ }^{2}$ For an introduction to this literature, see Levine (2005) or Aghion and Howitt (2009, ch. 6).

${ }^{3}$ Leijonhufvud $(1993,2006)$ has long been a forceful advocate of such an approach to macroeconomic modeling.
} 


\section{The model}

\subsection{Preliminaries}

Our model is a variant of the one developed by Howitt and Clower (2000), as modified by Howitt (2006 and 2008). ${ }^{4}$ The model attempts to portray, in an admittedly crude form, the mechanism by which economic activities are coordinated in a decentralized economy. It starts from the proposition that, in reality, almost all exchanges in an advanced economy involve a specialized trader ("shop owner") on one side or the other of the market. We add several components to this model so as to make it less stylized. In adding these new components, we have tried to make the structure and its macroeconomic aggregates comparable to the canonical New Keynesian analysis of Woodford (2003). That is, prices are set by competing firms acting under monopolistic competition, the rate of interest is set by a monetary authority following a Taylor rule, and consumer demands depend, inter alia, on current wealth. However, it is quite different from the New Keynesian framework in three important respects. First, we have introduced elements of search, in both goods (retail) markets and labor markets, whereas the canonical New Keynesian model has a Walrasian labor market and no search in the goods market. ${ }^{5}$ Second, unlike the fixed population of firms in the standard New Keynesian framework, we assume that firms are subject to failure and that the process of replacing failed firms is a costly one that disrupts established trading patterns. Third, instead of the perfect and complete set of contingent financial markets commonly assumed in the New Keynesian literature, we assume that the only available financial instruments are non-contingent bank deposits, bank loans to shops, and government-issued money and bonds.

\subsection{The conceptual framework}

\subsubsection{People, goods, and labor}

There is a fixed number $N$ of people, a fixed number $n$ of different durable goods, and the same number $n$ of different types of labor. Labor of type $i$ can be used only to produce good $i$. Time is discrete, indexed by "weeks" $t=1, \ldots, T$. There are 48 weeks per "year." In addition to the $n$ goods, there are four nominal assets: fiat money, bank deposits, bank loans, and bonds. Each of the last three is a promise to pay one unit of money ("dollar") next week.

Each person has a fixed type $(i, j)$, where $i \neq j$ and $i \neq j+1(\bmod n)$, meaning that each week he is endowed with one unit of labor of type $i$ (his "production good") and can eat only goods $j$ and $j+1(\bmod n)$ (his primary and secondary "consumption goods"). We assume that there is exactly one person of each type. Thus, the population of the economy is $N=n(n-2)$. In everything that follows, we set the number of goods $n$ equal to 50 , implying a population of $N=2400$ people.

\footnotetext{
${ }^{4} \mathrm{~A}$ model similar to the one developed here, but without private banks, is used by Ashraf and Howitt (2008) to investigate the effects of trend inflation on macroeconomic performance.

${ }^{5}$ Search and matching is now being introduced into labor markets in New Keynesian models by such authors as Gertler et al. (2008) and Blanchard and Gali (2010).
} 


\subsubsection{Shops, production, and trading}

Because no person can eat his own production good, everyone must trade to consume. Trading can take place only through facilities called "shops." Each shop is a combined production/trading operation. There are $n$ different types of shops. A shop of type $i$ is capable of buying type $i$ labor

with money, converting type $i$ labor into good $i$, and selling good $i$ for money. The number of shops of each type will evolve endogenously.

To trade with a shop, a person must form a trading relationship with it. Each person may have a trading relationship with at most one shop that deals in his production good, in which case that shop is his "employer" and he is one of its "employees," and at most one shop that deals in each of his consumption goods, in which case that shop is one of his "stores" and he is one of its "customers." Each person's trading relationships will evolve endogenously.

Each shop of type $i$ has a single owner, whose production good is $i$. Operating the shop entails a fixed overhead cost of $F$ units of type $i$ labor per week, and a variable cost of one unit of type $i$ labor per unit of good $i$ produced. When the shop is first opened, the owner also incurs a setup cost, that is, he must invest $S$ units of either of his consumption goods into the shop's fixed capital. All trade takes place at prices that are posted in advance by the shop. Specifically, each shop posts a retail price $p$ and a weekly wage rate $w$, each of which may be adjusted periodically.

There is no depreciation or other physical storage cost. Goods produced but not sold in a week are kept in inventory. Fixed capital cannot be used for any purpose (other than serving as collateral for loans) before the shop exits. Former shop owners that still hold fixed capital cannot consume it, but continue to hold it in hopes of selling it to another shop in special "firesale" markets to be described below. Likewise, they continue to hold the former shop's inventory until sold in a firesale market. The fixed capital and inventory still held by former shop owners are referred to as "legacy capital."

\subsubsection{Banks, deposits, and loans}

There is also a fixed number $m$ of bank "sectors," where $m$ is a divisor of the number of goods $n$. Agents are assigned to sectors depending on their production good, with the same number of agents in each sector. There is one bank per sector, which is owned by a single person in the sector. Each agent can only deal with the bank in his sector.

The two main functions of the bank is to accept deposits from people in its sector and to give out loans to shop owners. Loans are made with full recourse but are also collateralized by inventory and fixed capital. Each bank applies a haircut to collateral, that is, each week it establishes a "haircut" price $P_{h}$, and it will lend $P_{h}$ dollars for each unit of inventory or fixed capital it accepts as collateral. Banks cannot lend to consumers who are not shop owners.

Since loans are made with full recourse, if a shop owner is unable to repay his bank loan, the bank may seize all of his money and deposits, and also the shop's inventory and fixed capital until 
the value of what has been seized equals the amount owed. Foreclosure entails a resource cost. All seized assets stay on the bank's balance sheet until sold in the firesale markets.

In addition to loans and seized collateral, banks can hold money and government bonds. They also have access to a lender-of-last-resort facility from the government and are subject to bank regulation.

\subsubsection{Government and its policies}

In our model economy, the government conducts fiscal policy, monetary policy ( "central bank"), and bank regulation including deposit insurance ("FDIC"). Specifically, the government raises taxes, sets interest rates, lends to banks, regulates banks, and insures deposits. It does not purchase goods or labor but it does issue money and bonds, and services the interest on bonds through a sales tax on every retail transaction. It adjusts the ad valorem tax rate $\tau$ once per year.

The central bank pegs the interest rate $i$ on its bonds by buying or selling whatever quantity the banks wish to hold at that rate. It adjusts this rate every 4 weeks according to a Taylor rule. In addition, the central bank is engaged in forecasting the future GDP, inflation, and interest rates, and releases this information to the public.

As bank regulator, the government requires each bank to maintain equity at least equal to a fixed fraction $\kappa$ of the value of its "risky assets" (bank loans and seized collateral), where $\kappa$ is the "capital adequacy ratio." A bank that is not satisfying this constraint is declared to be "troubled," and is forbidden to initiate any new loans or to pay its owner a dividend.

A bank with negative equity is forced into failure. The FDIC seizes the bank owner's wealth and injects it into the bank, injects enough extra money to make the bank no longer troubled, and finds a new owner among the bank's depositors. The new owner adds any legacy capital that he might be holding to the bank's holdings of foreclosed capital, and adds his own deposits to the bank's equity. The recapitalized bank immediately reopens under the new owner, with all previous loans and deposits (except for the new owner's) unchanged.

\section{Protocol and behavioral rules}

Ideally, in an agent-based computational model, each agent (person, shop, bank, or government) should have complete autonomy in deciding what kind of action to take, including what kind of message to send to what other agents, and also in deciding when to initiate any action, without any central guidance. In practice, this level of autonomy could be implemented by giving every agent its own separate thread of control. But to do so would make the computer program extremely difficult, if not impossible, to debug. Moreover, it would entail a large overhead in the form of a protocol for coding and decoding a broad class of messages and for routing messages that can arrive 
at any time. ${ }^{6}$ To avoid these issues, we have followed the usual procedure of supposing a highly choreographed protocol that restricts the kinds of actions that any agent can take and forces them each week to proceed sequentially through the following nine stages:

\section{Entry}

2. Search and matching

3. Financial market trading

4. Labor and goods market trading

5. Monetary policy

6. Match breakups

7. Fiscal policy

8. Exit

9. Wage and price setting

The rest of this section describes the protocol and behavioral rules governing agents' actions at each stage. The complete $\mathrm{C}++$ code is available at http://www.econ. brown.edu/fac/peter howitt/working/BankFail.zip.

\subsection{Entry}

In the first stage, each person who is not already a shop owner or a bank owner becomes a potential entrant, or "entrepreneur," with probability $\theta / N$, where the parameter $\theta$ represents the supply of entrepreneurship.

Setup cost. An entrepreneur of type $(i, j)$ has an opportunity to open a shop of type $i$, provided he is able to immediately defray the setup cost of $S$ units (in total) of his two consumption goods. This fixed capital can be obtained from the entrepreneur's own legacy capital (if any), from firesale markets, or from stores with which the entrepreneur has a trading relationship. The entrepreneur is allowed to find out from the firesale markets and from his stores how much capital is available. All of each store's inventories are available at the respective posted retail price known to the entrepreneur at this stage. Each firesale market has a queue of sellers who are either banks offering to sell foreclosed capital or former shop owners offering to sell their legacy capital. All of that capital is

\footnotetext{
${ }^{6}$ Of all the agent-based computational macroeconomic models we are acquainted with, the EURACE model (Deissenberg et al., 2008; Cincotti et al., 2010) comes closest to the ideal of full autonomy. It appears, however, to run much more slowly than the present model, and we conjecture that this is largely attributable to the overhead of its elaborate protocol.
} 
available to the entrepreneur at a publicly known firesale price $P_{f}$ that was determined during the previous week. The determination of $P_{f}$ will be discussed in Section 4.4.

Credit line. Each entrepreneur may apply for a line of credit to his bank before deciding whether or not to enter, and the bank is allowed to approve the application unless, in the previous week, it was deemed by the government to be troubled, that is, to be in violation of its capital requirements. A line of credit can never be revoked until the shop exits, although a bank that is found to have deficient capital must limit the amount of loans outstanding to any shop owner. The bank's rules for credit line approval and maximum loan size determination will be made evident in Section 4.3 below.

An entrepreneur who has discovered that there is enough fixed capital available for him to enter and has also learned whether or not his bank approved his line of credit application must decide whether to enter the market or to let the opportunity lapse. We assume that he goes through the following decision process.

Business plan, financial viability, and profitability. First, the entrepreneur computes the nominal setup cost $S_{N}$, which is the minimum cost of acquiring fixed capital from all available sources, and formulates a business plan for his prospective shop, which consists of a wage rate $w$, a markup $\mu$, a sales target $y^{\operatorname{trg}}$, and a profit flow $\Pi$. He sets the wage rate equal to

$$
w=W\left(1+\pi_{w}^{*}\right)^{\frac{\Delta+1}{2}},
$$

which would make $w$ equal to the economy-wide average wage halfway through the fixed contract period of $\Delta$ weeks, provided that the average grows at the central bank's fixed target weekly inflation rate $\pi_{w}^{*}$ from last week's (publicly known) value $W$. The entrepreneur picks his markup randomly from a uniform distribution over $[0,2 \bar{\mu}]$, where $\bar{\mu}$ is a parameter measuring the average percentage markup over variable costs, and picks his sales target $y^{\text {trg }}$ randomly from a uniform distribution over $[1, n]$. These choices imply a profit flow equal to

$$
\Pi=\left[\left(\mu-i_{D}\right) y^{\operatorname{trg}}-\left(1+i_{D}\right)(F-1)\right] w
$$

where $i_{D}$ is the weekly nominal interest rate on deposits set by the bank last week. ${ }^{7}$

Given this business plan, the entrepreneur now conducts a financial viability test. Specifically, if he does not have enough financial wealth to pay for the setup cost and the fixed cost of operating the shop during the first month, $S_{N}+4(F-1) w$, then he will allow the entry opportunity to lapse. His financial wealth consists of money holdings, deposit holdings, and the credit limit

\footnotetext{
${ }^{7}$ This expression for target economic profit flow takes into account the opportunity cost of using money to pay for inputs. The target accounting profit of the shop owner is $\left[\mu y^{\operatorname{trg}}-(F-1)\right] w$, where 1 is subtracted from $F$ since the shop owner does not need to pay himself for own endowment. If, instead of producing, the agent put the money spent on inputs $\left(y^{\operatorname{trg}}+F-1\right) w$ in his deposit account, he would earn the interest $i_{D}\left(y^{\operatorname{trg}}+F-1\right) w$. Subtracting this opportunity cost from the target accounting profit, we get target economic profit flow $\Pi$ of the prospective shop owner.
} 
provided by the bank. The latter equals 0 if the entrepreneur has not been granted a line of credit, and $P_{h}(S+\mathrm{LI})$ otherwise, where LI is the entrepreneur's stock of legacy inventories. ${ }^{8}$ That is, as mentioned in Section 3.2.3, the loan is collateralized by fixed capital and inventory, to which a haircut $P_{h}$ is applied by the bank. The rule for setting $P_{h}$ will be stated in Section 4.4.

If the financial viability test is passed, the entrepreneur moves on to a profitability test. Specifically, he allows the entry opportunity to lapse unless

$$
\Pi>Y^{p}+\frac{P_{f} \cdot(\mathrm{LI}+S)}{V},
$$

where the right hand side is an estimate of the weekly cost of entering, namely the entrepreneur's current estimate of his permanent income, as described in Section 4.3 below, plus the equivalent permanent flow of income that could be achieved from selling his legacy capital LI $+S$ on the firesale markets and putting the proceeds in his bank account. Specifically, as will become evident in Section 4.5 below, $V$ is a capitalization factor equal to the present value of a nominal income stream, given the sequence of inflation rates and nominal interest rates that the central bank is projecting.

Market research. The entrepreneur also conducts "market research" before deciding whether to enter. In particular, he sends messages to two people, one of whom is a "comrade" (a randomly chosen person with the same production good as the entrepreneur) that does not own a shop, and the other of whom is a prospective customer (a randomly chosen person whose primary consumption good is the same as the entrepreneur's production good). The message to the comrade declares the wage rate $w$ that the entrepreneur will post if he decides to open shop, and the message to the prospective customer declares the retail price he plans to post

$$
p=\frac{1+\mu}{1-\tau} w
$$

This price represents an after-tax markup of $\mu$ over the marginal cost $w$.

The comrade must answer whether or not he will consent to forming an employment relationship with the new shop if it opens, and the prospective customer must answer whether he is willing to form a customer relationship. They are assumed to respond according to the following myopic rules. The comrade accepts if and only if

$$
w^{\mathrm{eff}}<\frac{w}{1+\pi_{w}^{*}}
$$

where $w^{\text {eff }}$ represents the effective wage experienced by the comrade last period (see equation (4)) if the comrade is currently employed, and is equal to zero otherwise. ${ }^{9}$ The prospective customer,

\footnotetext{
${ }^{8}$ Note that, in contrast to legacy fixed capital, legacy inventories cannot be part of $S$, since they are in units of a person's production good while $S$ must be incurred in units of consumption goods.

${ }^{9}$ The inflation adjustment is made in anticipation that, on average, an employer's wage will rise at the target inflation rate.
} 
on the other hand, will accept if and only if

$$
p^{\mathrm{eff}}>\frac{p}{1+\pi_{w}^{*}},
$$

where $p^{\text {eff }}$ represents the effective price he experienced last period for the entrepreneur's production good (see equation (5)) if he has a store for that good, and is infinite otherwise.

Entry decision. The entrepreneur then makes his entry decision. He decides to enter if: 1) he can raise the necessary amount of fixed capital to cover the setup cost; 2) his business plan passes financial viability and profitability tests; and 3) both the comrade and the prospective customer respond affirmatively to his invitation to form a relationship with the new shop. If any of the above three conditions is violated, the entrepreneur decides not to open a shop, and the opportunity to do so lapses. Otherwise, he moves on to purchase enough fixed capital to cover his setup cost, part of which, up to the credit limit, may be covered by the bank loan if his credit line application has been approved. He then opens the shop with a posted wage $w$, a posted price $p$, a markup $\mu$, a sales target $y^{\text {trg }}$, an inventory level equal to the entrepreneur's legacy inventory LI, and an "input target" equal to

$$
x^{\operatorname{trg}}=y^{\operatorname{trg}}+F+\lambda_{I}\left(y^{\operatorname{trg}}-I\right),
$$

where $\lambda_{I}$ is the weekly inventory adjustment speed and $I$ is current inventories, which for a new shop are just equal to the entrant's legacy inventories LI. Implicit in equation (3) is a desired inventory level equal to one week's sales.

The comrade becomes the new shop's actual employee with an effective wage of $w\left(1+\pi_{w}^{*}\right)^{-1}$, and the potential customer becomes its actual customer with an effective price of $p\left(1+\pi_{w}^{*}\right)^{-1}$. The entrepreneur becomes a shop owner and terminates any employment relationship he might have had with another employer.

\subsection{Search and matching}

Next, each person is given an opportunity to search for possible trading relationships. This comprises both job search and store search. ${ }^{10}$

Job search. Each person who is not a shop owner engages in job search with probability $\sigma$. Job search consists in asking one comrade what his effective wage is. If the comrade is not a shop owner and his effective wage exceeds the searcher's, the latter will ask the comrade's employer for a job. If the comrade is a shop owner, that is, is an employer himself, the searcher will ask him for a job if and only if inequality (1) holds, where $w$ is the latest posted wage at the comrade's shop. In each case, the employer accepts the searcher as a new worker if and only if the amount of

\footnotetext{
${ }^{10}$ We thus take the approach of Stigler (1961), who modeled search as a search for stores with which one can engage in repeated exchanges, instead of a search for someone with whom to engage in a one-off exchange. This is also the Phelps-Winter (1970) "customer market" view of product markets. It means that the exit of a shop involves the destruction of organizational capital in the form of what would otherwise have been a long-term customer relationship.
} 
labor input he used last period is less than or equal to his current input target. If this condition holds, the searcher terminates his pre-existing employment relationship (if any) and forms a new one, changing his effective wage to either his comrade's or to $w\left(1+\pi_{w}^{*}\right)^{-1}$ if the comrade is a shop owner.

Store search. Store search is undertaken by every person. It comprises referral-based and direct search. First, the person asks a "soulmate" (a randomly chosen person with the same primary consumption good) for his effective retail prices. The searcher decides to switch to a soulmate's store if and only if the soulmate's effective price for that good is less than the searcher's. Second, the person engages in direct search, which consists in asking a randomly chosen shop if it trades either of his consumption goods and, if so, what the posted prices are. The searcher decides to switch if and only if inequality (2) holds, where $p$ is the shop's latest posted price. If the searcher switches for either of his consumption goods, he terminates the pre-existing customer relationship with a shop of the corresponding type and forms a new one, revising his effective price to either his soulmate's, in the case of referral-based search, or to $p\left(1+\pi_{w}^{*}\right)^{-1}$ in the case of direct search.

\subsection{Financial market trading}

At this stage, all financial transactions take place except for loans acquired to finance the purchase of fixed capital by entrants, as described in Section 4.1, and the purchase of working capital in firesale markets during the trading stage that comes next.

Bank regulation and lending policy. Each bank's balance sheet looks as follows:

\begin{tabular}{l|l}
\multicolumn{1}{c|}{ Assets } & Liabilities and Equity \\
\hline Commercial loans & Deposits \\
Seized collateral & Loans from CB \\
Government bonds & Equity \\
Reserves &
\end{tabular}

On the assets side, commercial loans are loans made by the bank to shop owners, measured as the dollar value of principal and interest payable this week; seized collateral consists of inventories and fixed capital seized by the bank from defaulting shops, valued at the firesale price; government bonds are bonds held by the bank, evaluated as the amount due this week; and reserves are holdings of high-powered money, that is, cash and money on deposit with the central bank wing of the government. The liabilities of a bank consist of deposits held by agents assigned to this bank and loans from the central bank. Equity is calculated as the bank's assets minus its liabilities.

At the beginning of this stage, each bank updates its equity after the previous week's transactions and the entry stage. Before any financial market trading takes place, banks in all sectors are examined by the regulatory branch of the government. Banks with negative equity fail. When a bank fails, the government agency (FDIC) first injects money to fully recapitalize the new bank so that it fulfills the minimum capital requirement, discussed further below. Then, a new owner 
is chosen from the list of the failed bank's customers who do not own a shop. In particular, the richest amongst them (i.e., the one with the highest sum of cash and deposit holdings) becomes the new owner. If the new bank owner has some legacy capital, it is placed on the bank's balance sheet (seized collateral account) and participates subsequently on the firesale market along with other foreclosed assets that the bank has. Equity is again updated to take into account these changes to the balance sheet. Note that no deposits are ever destroyed during the bank failure process because the government's policy of injecting new capital and finding a new owner serves to fully insure all deposits.

Next, all banks are checked for capital adequacy. In particular, the ratio of a bank's equity to its risk-weighted assets must be greater or equal to $\kappa$, the capital adequacy ratio ${ }^{11}$ :

$$
\text { Equity } \geqslant \kappa \cdot(\text { Commercial loans }+ \text { Seized collateral }) \equiv \text { Required capital. }
$$

If this condition is violated, that is, if equity is less than the required capital, the corresponding bank becomes a troubled bank. Troubled banks are not allowed to provide new loans (although they are allowed to roll over outstanding loans) and their owners cannot receive dividends. If the bank is not troubled, it now decides the probability $P_{\mathrm{CL}}$ with which it approves any new applications for a credit line this week and during the entry stage next week. If its equity is less than its required capital, it sets $P_{\mathrm{CL}}$ equal to zero. Otherwise,

$$
P_{\mathrm{CL}}=\min \left\{l \cdot\left(\frac{\text { Equity }}{\text { Required capital }}-1\right), 1\right\},
$$

where $l$ is the slope parameter of a bank's loan approval schedule. This means that a loan is granted with probability 1 if required capital as a fraction of equity does not exceed $l /(1+l)$. Otherwise, as the financial position of a bank deteriorates, that is, as the ratio of equity to required capital falls, the probability of loan approval decreases linearly in that ratio until it equals zero when the bank is on the brink of being in trouble.

At this point, each bank also sets the interest rate $i_{L}$ on all new loans that will be issued this week and the interest rate on all deposits $i_{D}$ held at the end of this stage. The bank always sets $i_{D}=i_{w}$ and $i_{L}=i_{w}+s / 48$, where $i_{w}$ is the weekly nominal interest rate set by the monetary authority, as discussed in Section 4.5, and $s$ is a fixed annual spread, common across all banks. We suppose that these choices are constrained by regulations that prevent a bank from exploiting the monopoly power implied by the limitation of one bank per sector in our setup.

Budget planning. Next, people of all types do their budget planning. Since the only reason for holding money is in order to spend it during the next stage, each person must first decide on his

\footnotetext{
${ }^{11}$ This formulation mimics the Basel I capital accord. The assigned risk weights ( 1 for loans and seized collateral, and 0 for government bonds and reserves) come directly from Basel I recommendations. In one of our policy experiments discussed in Section 8.3, we will allow the capital adequacy ratio $\kappa$ to vary depending on the central bank's estimate of the current economic situation.
} 
planned consumption expenditures for the week. In preparation for this decision, everyone first adjusts his permanent income according to the following adaptive rule:

$$
\Delta Y^{p}=\lambda_{p}\left(Y-Y^{p}\right),
$$

where $Y$ is actual income from the previous period and $\lambda_{p}$ is the weekly permanent income adjustment speed. Here, $Y$ is equal to last period's profit for shop owners and the effective wage rate for all other people. Then, each person adjusts $Y^{p}$ for estimated weekly inflation assuming that inflation is taking place each week at the target rate, that is, he multiplies $Y^{p}$ by $\left(1+\pi_{w}^{*}\right)$.

We assume that each person sets planned consumption expenditures this week equal to a fixed fraction $v$ of total wealth. The total wealth $E$ of each person is the sum of financial wealth $A$ and the capitalized value of permanent income. Thus,

$$
E=v \cdot\left(A+V \cdot Y^{p}\right),
$$

where $V$ is the same capitalization factor mentioned in Section 4.1. The financial wealth $A$ of people who don't own a shop or a bank is the sum of their money holdings and bank deposits, plus the firesale value of their legacy capital (if any). For bank owners, financial wealth consists of money holdings and, if the bank is not troubled, the bank's equity after subtracting required capital. For shop owners, it is equal to the sum of money and deposit holdings minus outstanding loans.

Financial transactions. Next, people of all types reallocate their portfolios of financial assets. Having chosen $E$, each person chooses the amount of cash $M$, taking into account the constraints he faces. Consider first a person who does not own a bank or a shop. He enters this stage owning $\bar{M}$ in cash and $\bar{D}$ in deposits, and must choose $M$ and $D$ with which to leave this stage, subject to neither being negative and subject to

$$
D=(\bar{M}+\bar{D}-M)\left(1+i_{D}\right)
$$

We use the convention of measuring $D$ as the amount owed by the bank at the next stage of financial market trading. If $E \leqslant \bar{M}+\bar{D}$, the person sets $M=E$ and leaves the rest in his bank deposit account. Otherwise, he withdraws all of his deposits and revises planned expenditure so that $E=M=\bar{M}+\bar{D}$. The idea here is that he will need to have $E$ in the form of money when he visits his stores. But he does not know whether he will be paid his income before or after shopping for goods, so he plans to carry $E$ out of the financial market to ensure against being unable to fulfill his expenditure plans. ${ }^{12}$

\footnotetext{
${ }^{12}$ This motivation for a precautionary demand for money is similar to the "stochastic payment process" that Patinkin (1965) used to rationalize putting money in the utility function. In this case we are using it to justify what looks like a conventional cash-in-advance constraint.
} 
Next, consider a bank owner. If he owns a troubled bank, that is, if the minimum capital requirement is violated, he cannot receive dividends and his expenditure is bounded by current money holdings $\bar{M}$. If the latter exceeds $E$, the remaining $\bar{M}-E$ goes into the bank; otherwise, he sets $E=M=\bar{M}$. If the owned bank is not troubled, then he employs his financial wealth $A$ in the following way. If $E \leqslant A$, he sets $M=E$ and leaves the surplus $A-E$ in bank equity; otherwise, he sets $E=M=A$.

Finally, consider a shop owner. A shop owner can hold money and deposits, and can also take a bank loan $L$ (measured as the amount owing next week) up to his credit limit. If the shop has already been granted a credit line earlier, his credit limit is set equal to the haircut value of his eligible collateral (fixed capital and inventories) if his bank is not troubled, or the minimum of the pre-existing loan $\bar{L}$ and the haircut value of his eligible collateral if he has a line of credit with a troubled bank. ${ }^{13}$ If the shop does not yet have a credit line, the shop owner applies for one at this stage and obtains it with probability $P_{\mathrm{CL}}$, as described above, if his bank is not in trouble (otherwise, his application is rejected). His credit limit CL is then equal to $P_{h}(S+I)$ if the credit line is granted, and 0 otherwise, where $I$ is his shop's current inventory holding and $P_{h}$ is the haircut price.

The shop owner's constraints in his financial transactions are:

1. $M \geqslant 0, D \geqslant 0, L \geqslant 0$

2. $M+D /\left(1+i_{D}\right)+\bar{L}=\bar{M}+\bar{D}+L /\left(1+i_{L}\right)$;

3. $L \leqslant \mathrm{CL} \cdot\left(1+i_{L}\right)$.

It is possible for a shop owner to satisfy all of his constraints if and only if

$$
\bar{M}+\bar{D}+\mathrm{CL} \geqslant \bar{L} .
$$

Otherwise, he is unable to repay his loan. In the latter event, his shop is declared bankrupt, and the bank seizes all his cash, fixed capital, and inventories, and nullifies his deposits. Moreover, the shop must close in the exit stage this week. A bank that has seized capital adds the fraction $1-C_{b}$ to its holdings of seized collateral and joins the queue for the firesale market in each of those goods (if not already there), where $C_{b}$ is the resource cost of foreclosure.

The shop owner's desired money holding is the amount needed to cover not only his planned consumption expenditure but also his target wage bill $\mathrm{WB}^{\mathrm{trg}}$, equal to his current posted wage times his current input target $x^{\text {trg }}$ minus one (since he does not have to pay himself for own endowment). Before computing $\mathrm{WB}^{\text {trg }}$ the shop owner updates his input target using equation (3) above.

Based on the shop owner's financial situation, the following cases are possible:

1. If $A+\mathrm{CL}<0$, the shop goes bankrupt, as described above.

\footnotetext{
${ }^{13}$ Recall that collateralized rollover of existing loans is always allowed, even if the bank is troubled.
} 
2. If $0 \leqslant A+\mathrm{CL}<\mathrm{WB}^{\mathrm{trg}}$, the shop owner sets $E=0$, withdraws all of his deposits, and borrows as much as he can from the bank (CL). His cash holdings after repaying the loan are thus $M=A+\mathrm{CL}$.

3. If $\mathrm{WB}^{\operatorname{trg}} \leqslant A+\mathrm{CL}<\mathrm{WB}^{\operatorname{trg}}+E$, the shop owner withdraws all deposits, borrows as much as he can from the bank, and sets $E=A+\mathrm{CL}-\mathrm{WB}^{\text {trg}}$; that is, his priority is to have enough cash to cover the target payroll. As before, $M=A+\mathrm{CL}$.

4. If $A<\mathrm{WB}^{\operatorname{trg}}+E \leqslant A+\mathrm{CL}$, the shop owner can afford to finance the entire wage bill and desired consumption expenditure, but cannot pay off the whole outstanding loan. He then pays off as much of the loan as he can, and sets $D=0$ and $M=\mathrm{WB}^{\operatorname{trg}}+E$.

5. If $\mathrm{WB}^{\mathrm{trg}}+E \leqslant A$, the shop owner can afford the entire wage bill plus desired consumption expenditure, and can also repay the whole outstanding loan. In this case the shop owner pays off the loan, sets $M=\mathrm{WB}^{\mathrm{trg}}+E$, and puts his remaining wealth into his deposit account.

After all agents are done with their portfolio adjustments, a bank's reserves could potentially become negative. We suppose that the bank is able to get cash from the government instantaneously to honor all withdrawals but that its deposit account with the central bank is debited accordingly and can become overdrawn. At this point, the government pays the amount owing on its bonds to the banks that are holding them. If a bank still has negative reserves, it must borrow from the central bank enough to make its reserves nonnegative again. The annual rate charged on advances to banks is $i+s_{d}$, where $s_{d}$ is a fixed premium (the CB's discount rate). The bank invests any positive reserves in new government bonds.

\subsection{Labor and goods market trading}

Firesale markets trading. This stage starts with trade in the firesale markets. Each shop of type $i$ can place an order for any amount $Q$ of good $i$ subject to the finance constraint

$$
D+\mathrm{CL} \geqslant P_{f} Q
$$

If $Q>0$, the shop owner is matched to the first seller (if any) in the $i^{\text {th }}$ queue. If the first seller in the queue cannot fulfill the whole order, he sells what he has and the turn goes to the next seller in the queue, and so on, until either the order is fulfilled or the queue runs out of sellers. The payment for inventories bought at the firesale market is in dollars due at the beginning of next week.

A shop is assumed to place no order $(Q=0)$ if its actual inventories are greater than its inventory target, which is identically equal to its sales target. If the desired order is positive, the shop's owner has a credit line, and his bank is not troubled, he places an order equal to $Q$, the difference between the inventory target and shop's actual inventory. Otherwise the shop can only afford the amount $D / P_{f}$, so the shop orders an amount equal to $\min \left\{Q, D / P_{f}\right\}$. The shop pays for 
all successfully executed orders first out of the owner's deposits and then, if necessary, by increasing the size of the owner's bank loan (taking an "express loan" for the amount that he lacks).

Each shop's inventory is reduced by the amount $\min \{F, \bar{I}\}$ to cover the fixed cost, where $\bar{I}$ is the inventory after the firesale transactions. If $F>\bar{I}$, then all input held by the shop must be used to defray the fixed cost, while inventory remains equal to zero, until the fixed cost has been fully covered. After that, any input received adds one for one to inventory.

Next, each person in turn engages in labor market trading (with his employer) and goods market trading (with his stores), starting with the store trading his primary consumption good. With probability $1 / 2$ he either first trades with his employer or with his stores.

Labor market trading. Labor market trading proceeds as follows. If the person is a shop owner (i.e., if he is self-employed), he simply uses his unit endowment as input. If the person has no employer, then nothing happens when it is his turn to engage in labor market trading. Otherwise, if he has an employer with positive money holding, he offers to trade his endowment in exchange for the "effective wage"

$$
w^{\mathrm{eff}}=\min \{w, M\}
$$

where $w$ is the employer's posted wage and $M$ is the employer's money holding just prior to this trade. If $M=0$, then the employee is not required to deliver his input but his employment relationship with the shop remains intact.

The employer is not obligated to accept an employee's offer to trade. He can instead choose to lay the worker off, in which case no input is delivered, no payment is made, and the employment relationship is severed. We assume that the employer chooses to do so if and only if: (a) the shop's labor input is already more than its input target, and (b) the ratio of its inventory to its sales target exceeds a critical threshold value IS $>1$. In general, there are four ways for a person to become unemployed in our model economy: 1) have an employer who is broke when offered to deliver the input; 2) become laid off; 3) have a match break up randomly (see Section 4.6); and 4) have an employer exit the market (see Section 4.8). Note that the employment relationship is retained only in the first case.

Goods market trading. Goods market trading happens in the following manner. First, the customer learns the price currently posted by both of his stores. Then, when a person visits a store with positive inventory $I$, he can place an order for some amount $c$, subject to the cash-in-advance constraint $p c \leqslant M$, where $p$ is the posted retail price and $M$ is the person's money holding just prior to the visit. The store then gives the person an amount $c^{\text {eff }}=\min \{c, I\}$ in exchange for the amount $p c^{\text {eff }}$ of money. The person's effective price for that good is defined as

$$
p^{\mathrm{eff}}=p c / c^{\mathrm{eff}} \text {. }
$$


If $I=0$ or the person does not have a store for that good, nothing happens at this stage of goods trading except that the person's effective price is set to $+\infty$. For every dollar spent by a customer, the shop owner receives $1-\tau$ dollars, with the rest going to the government to cover the sales tax.

We assume that each customer chooses his desired consumption bundle $\left(c_{1}, c_{2}\right)$ to maximize his utility function

$$
c_{1}^{\varepsilon /(\varepsilon+1)}+c_{2}^{\varepsilon /(\varepsilon+1)}
$$

with a "demand parameter" $\varepsilon>0$, subject to his budget constraint. If he has established relationships with stores for both of his consumption goods, the budget constraint is

$$
p_{1} c_{1}+p_{2} c_{2}=E,
$$

where $E$ is the planned expenditure determined in the previous stage and the $p_{i}$ 's are the stores' posted prices. If he has an established relationship with only one store with posted price $p$, then he orders the amount $E / p$ from that shop.

Average wage, firesale price, and haircut price. At this point, the government computes the average wage rate $W$, which is the employment-weighted average across all shops, and announces the result to all agents. All firesale prices are then set for next week at the value

$$
P_{f}=\frac{1}{2} \cdot W \cdot\left(1+\pi_{w}^{*}\right)
$$

where $\pi_{w}^{*}$ is the central bank's weekly inflation target. Our rationale here is that $P_{f}$ splits the difference between the value of inventory to a shop owner (approximately the marginal cost of producing an extra unit) and its value to a seller in the firesale queue for whom the goods have no direct use. The target inflation factor is added in anticipation of next week's increase in the marginal cost.

Finally, each bank sets its haircut price $P_{h}$ for next week. The haircut price is set by the bank proportionally to the estimated marginal cost of production. Thus,

$$
P_{h}=h \cdot W \cdot\left(1+\pi_{w}^{*}\right)
$$

where $h$ is the loan-to-value ratio imposed by bank regulation that we assume is binding on the banks, and we measure value as the replacement cost of the collateral to the borrower. All banks will therefore have the same haircut price at any given time.

\subsection{Monetary policy}

Interest rate setting. Next is the stage in which the central bank (CB) sets the nominal interest rate $i$. First, it checks whether this is a fixed action date, which is true every fourth week. If not, this stage is skipped and the interest rate remains unchanged. If it is a fixed action date, then the 
CB calculates average real GDP per week (the sum of each shop's input in excess of its fixed cost, over the past "month" (4 weeks), divided by 4) and the current price level (GDP deflator). The government also keeps track of the values of year-to-year inflation factors, price levels, and average real weekly GDP for the last 12 months.

The annual rate of interest $i$ is set according to a Taylor rule, that is,

$$
\ln (1+i)=\max \left\{\ln \left(1+i^{*}\right)+\gamma_{\pi}\left[\ln (1+\pi)-\ln \left(1+\pi^{*}\right)\right]+\gamma_{y}[y-\tilde{y}], 0\right\},
$$

where $\gamma_{\pi}$ and $\gamma_{y}$ are fixed coefficients, $1+\pi$ is the inflation factor over the past 12 months, $\pi^{*}$ is the fixed inflation target, $y$ is the current 3-months moving average for the weekly average log GDP, $\tilde{y}$ is the CB's evolving estimate of weekly $\log$ potential output, and $i^{*} \equiv r^{*}+\pi^{*}$, where $r^{*}$ is the evolving target for the long-run real interest rate. The rule, as specified in equation (6), respects the zero lower bound on nominal interest rates. The weekly interest rate is determined according to $1+i_{w}=(1+i)^{1 / 48}$.

Adjusting targets and learning. The real interest rate target is adjusted as follows:

$$
\Delta r^{*}=\eta_{r}\left(\pi-\pi^{*}\right) \cdot f\left(\pi, r^{*}\right), \quad f\left(\pi, r^{*}\right) \equiv \frac{r^{*}}{\sqrt{\eta_{r}^{2}\left(\pi-\pi^{*}\right)^{2}+\left(r_{0}^{*}\right)^{2}}},
$$

where $\eta_{r}$ is a fixed target interest rate adjustment coefficient, $r_{0}^{*}$ is the initial real interest rate target, and $f\left(\pi, r^{*}\right)$ is a "squasher." So, the interest rate target is increased or decreased as the current inflation rate exceeds or falls short of the government's target. The squasher makes sure that this change is symmetric (S-shaped) around the point $\pi=\pi^{*}$ and never causes $r^{*}$ to become negative. Around the point $\left(\pi, r^{*}\right)=\left(\pi^{*}, r_{0}^{*}\right), \Delta r^{*} \approx \eta_{r}\left(\pi-\pi^{*}\right)$, that is, the adjustment of the target interest rate is roughly proportional to the deviation of actual inflation from the CB's target inflation rate.

The CB models the year-to-year behavior of weekly log GDP as the following AR(1) process:

$$
y_{t}=\alpha_{y}+\lambda_{y} y_{t-1}+\xi_{y t}
$$

where $\tilde{y} \equiv \alpha_{y} /\left(1-\lambda_{y}\right)$ is defined as potential weekly $\log$ GDP and $\xi_{y t}$ is an i.i.d. disturbance term. We assume that the $\mathrm{CB}$ begins to adjust all the estimates and targets after $T_{\mathrm{cb}}$ years. Given the initial estimates $\left(\widehat{\alpha}_{y, t-1}, \widehat{\lambda}_{y, t-1}\right)$, the CB re-estimates these parameters once per year using the following recursive OLS scheme on annual data ${ }^{14}$ :

$$
\left(\begin{array}{c}
\widehat{\alpha}_{y t} \\
\widehat{\lambda}_{y t}
\end{array}\right)=\left(\begin{array}{c}
\widehat{\alpha}_{y t-1} \\
\widehat{\lambda}_{y t-1}
\end{array}\right)+\left(\begin{array}{c}
\overline{y_{t-1}^{2}}-y_{t-1} \bar{y}_{t-1} \\
y_{t-1}-\bar{y}_{t-1}
\end{array}\right) \cdot \frac{y_{t}-\widehat{\alpha}_{y t-1}-\widehat{\lambda}_{y t-1} y_{t-1}}{t \bar{y}_{t-1}^{2}-t\left(\bar{y}_{t-1}\right)^{2}}
$$

\footnotetext{
${ }^{14}$ Actually, we suppose that the CB starts directly with an estimate $\tilde{y}_{0}$ of potential output, which it uses in the Taylor rule for the first $T_{\mathrm{cb}}$ years. It then uses the recursive OLS scheme starting with $\widehat{\alpha}_{T_{\mathrm{cb}}-1}=\left(1-\widehat{\lambda}_{y 0}\right) \tilde{y}_{0}$.
} 
where $\bar{y}_{t-1}$ is the average lagged log GDP in the learning period sample and $\overline{y_{t-1}^{2}}$ is the average squared lagged log GDP. The new estimate of log potential GDP, equal to $\widehat{\alpha}_{y t} /\left(1-\widehat{\lambda}_{y t}\right)$, is the one subsequently used in the Taylor rule.

Similarly, the CB models the annual evolution of inflation as the following AR(1) process:

$$
z_{t}=\lambda_{\pi} z_{t-1}+\xi_{\pi t}
$$

where $z_{t} \equiv \ln \left(1+\pi_{t}\right)-\ln \left(1+\pi^{*}\right)$ and $\xi_{\pi t}$ is an i.i.d. shock. Again, given the initial estimate $\widehat{\lambda}_{\pi 0}$, the $\mathrm{CB}$ recursively re-estimates this parameter on an annual basis after the learning period is over, that is,

$$
\widehat{\lambda}_{\pi t}=\widehat{\lambda}_{\pi t-1}+\frac{z_{t} z_{t-1}-\widehat{\lambda}_{\pi t-1} z_{t-1}^{2}}{t \overline{z_{t-1}^{2}}} .
$$

Capitalization factor. The CB's projections of inflation and GDP, based on the above equations, are then fed into the Taylor rule in equation (6) to compute the future path of interest rates, under the assumption that the coefficients and the values of $\tilde{y}$ and $i^{*}$ will remain unchanged. The CB uses these predictions to calculate a capitalization factor $V$, which people can use to estimate the present value of income given their estimates of permanent income, and announces its value to all people. Specifically,

$$
V=\sum_{t=1}^{\infty}\left(\frac{1}{1+\pi_{w t}}\right) \prod_{k=1}^{t}\left(\frac{1+\pi_{w k}}{1+i_{w k}}\right),
$$

where $\pi_{w k}$ and $i_{w k}$ are the inflation rate and the interest rate projected for week $k$.

A person who could count on these projections, who would never be rationed in purchasing consumption goods, who faced consumption prices that rose each period at the economy-wide rate of inflation, who held only enough cash to satisfy the cash-in-advance constraint each period, who invested the rest of his financial wealth in deposits yielding $i_{w t}$, and who had a constant perpetual stream of income, starting this week, equal to $Y^{p}$ in today's $(t=1)$ dollars, would be able to afford any consumption stream $\left\{c_{t}\right\}_{1}^{\infty}$ satisfying $^{15}$

$$
\sum_{t=1}^{\infty} R_{t} c_{t}=\frac{A_{1}+V Y^{p}}{P_{1}}
$$

where each $R_{t}$ is the present value of a real dollar in week $t$, defined recursively as

$$
R_{1}=1, \quad R_{t+1}=\frac{1+\pi_{w t}}{1+i_{w t}} R_{t} \quad \forall t \geqslant 1 .
$$

\footnotetext{
${ }^{15}$ To see this, note that the flow budget constraint facing the individual each period would be $A_{t+1}=$ $\left(A_{t}-P_{t} c_{t}\right)\left(1+i_{w t}\right)+P_{t} Y^{p} / P_{1}$, which, together with the no-Ponzi-game condition, is equivalent to equation (8).
} 
The division of each term in equation (7) by $1+\pi_{w t}$, and the fact that income at $t$ is discounted by $R_{t+1}$ in equation (8) while consumption is only discounted by $R_{t}$, both reflect the cash-in-advance constraint; the dollar earned in $t$ cannot be spent until $t+1$.

Note that the expenditure function from Section 4.3 would apply if the person knew for certain what future incomes and interest rates would be, and were choosing $E$ so as to maximize a standard intertemporal additive logarithmic utility function with a weekly rate of time preference $\rho_{w}=$ $v /(1-v)$, subject to the lifetime budget constraint in equation (8). We will use this interpretation of the expenditure function when calibrating the model, and will calibrate it in terms of the annual rate of time preference $\rho$, defined by $(1+\rho)=\left(1+\rho_{w}\right)^{48}$.

\subsection{Match breakups}

The established trading relationships may break up randomly. In particular, each person in the economy who does not own a shop is subjected to a probability $\delta$ of quitting the labor and goods markets, which entails the unconditional severance of all current trading relationships by the person with his employer and his consumption stores.

\subsection{Fiscal policy}

Next comes the stage in which the retail sales tax rate $\tau$ is adjusted. This happens only once a year, in the last week of the year. In all other weeks, this stage is bypassed and $\tau$ remains unchanged.

When deciding on a new tax rate, the government first calculates the size of the government debt (normalized by the price level) relative to annual estimated potential GDP. It then sets the tax rate equal to a value $\tau^{*}$, which is the value that would leave the debt-to-GDP ratio undisturbed in the no-shock equilibrium to be described in Section 5.1, plus an adjustment factor that is proportional to the difference between the actual and the target debt-to-GDP ratio $b^{*}$ :

$$
\tau=\tau^{*}+\lambda_{\tau} \cdot\left(\frac{B}{P\left(1+i_{w}\right)\left(48 \cdot e^{\tilde{y}}\right)}-b^{*}\right)
$$

where $B$ is the total stock of issued government bonds, $P$ is the current price level, and $\lambda_{\tau}$ is the adjustment coefficient.

\subsection{Exit}

Now, each shop has an opportunity to exit. In particular,

1. Each shop whose owner is bankrupt must exit;

2. Each remaining shop exits for exogenous reasons with probability $\delta$;

3. Each shop can choose voluntarily to exit. 
We assume that a shop will voluntarily exit with certainty if it cannot afford to pay for the coming week's fixed overhead cost, that is, if

$$
A+\mathrm{CL}<w(F-1)
$$

where $A$ is the shop owner's financial wealth, computed as in Section 4.3 above.

The only other situation in which a shop will voluntarily exit is if it is unprofitable, in which case it will exit with a fixed probability $\phi$. In computing profitability, the shop owner takes into account the opportunity cost of his labor services, that could be earning a wage, and the interestopportunity cost of maintaining the shop's fixed capital and inventory. Specifically, the shop owner will decide that the shop is unprofitable if one of the following two cases applies:

$$
\begin{aligned}
& \text { (a) } A+P_{f}(I+S) \geqslant 0 \text { and } V \cdot W+P_{f}(I+S)>V \cdot \Pi^{e} \text {; } \\
& \text { (b) } A+P_{f}(I+S)<0 \text { and } V \cdot W>V \cdot \Pi^{e}+A
\end{aligned}
$$

where $I$ is the shop's inventory, $S$ is his fixed capital, $W$ is the current economy-wide average wage, $P_{f}$ is the firesale price, $V$ is the capitalization factor, and $\Pi^{e}$ is the shop owner's permanent income (expected profit from staying in business). Each case implies that the owner's tangible plus human wealth would increase as a result of exit, under the assumption that he could get a job paying the wage $W$. In case (a) he would be able to repay his loan in full, although perhaps allowing some inventory and fixed capital to be seized, so in the event of exit his tangible plus human wealth would go from $V \cdot \Pi^{e}+A$ to $V \cdot W+P_{f}(I+S)+A$. In case (b) he would be unable to repay his loan in full, so upon exit his tangible plus human wealth would go from $V \cdot \Pi^{e}+A$ to $V \cdot W$.

Once a shop exits for any reason, all trading relationships (with both employees and customers) are dissolved and the shop owner has to repay his bank loan to the extent possible (bankrupt shops have already settled their loans). If the sum of shop owner's money and deposits exceeds the bank loan, he repays the whole loan to the bank. Otherwise, the bank seizes capital as described in Section 4.3 above, evaluating the capital at firesale prices. Banks with seized capital and former shop owners with non-seized capital now join the appropriate firesale queues if not already there. Upon exit, the former shop owner resets his permanent income to $W$.

\subsection{Wage and price setting}

In the final stage of weekly activities, each shop has an opportunity to update its posted wage and retail price. Wage and price changes are not communicated automatically to the shop's employees and customers until the start of next period's trading.

Each shop first updates its sales target $y^{\text {trg }}$, setting it equal to the current week's actual sales. Then, it proceeds to update the shop's wage, but only if the last wage change was $\Delta$ weeks ago, where the length $\Delta$ of the contract period is a parameter of the model. Given that the current 
week is indeed a wage-updating week for the shop being considered, its wage is set equal to

$$
w=\bar{w} \cdot\left[\left(1+\beta \cdot\left(\overline{x^{\operatorname{trg}}} / \overline{x^{\mathrm{pot}}}-1\right)\right) \cdot\left(1+\pi^{*}\right)\right]^{\Delta / 48},
$$

where $\bar{w}$ is the pre-existing wage, $\overline{x^{\text {trg }}}$ is the average input target over the past $\Delta$ weeks, and $\overline{x^{\text {pot }}}$ is the average potential input over the same period (i.e., the number of people having an employment relationship with the shop, even if they were laid off or if they refused to work because they were not paid). ${ }^{16}$ The parameter $\beta$ hence indexes the degree of wage and price flexibility in the economy. This wage adjustment anticipates inflation over the coming contract period at an annual rate equal to the CB's target $\pi^{*}$.

Every week, each shop has an opportunity to revise its retail price. Its "normal" price is $p^{\text {nor }}=(1+\mu) w /(1-\tau)$, which would equate its after-tax price to its wage times its desired markup, corresponding to the rule discussed earlier in Section 4.1. The shop will choose this normal price unless its inventories are too far from the desired level, namely its target sales. Specifically, it will set

$$
p= \begin{cases}p^{\text {nor }} \cdot \delta_{p}, & \text { if } I>y^{\operatorname{trg}} \cdot \mathrm{IS} \\ p^{\text {nor }} \cdot \delta_{p}^{-1}, & \text { if } I<y^{\operatorname{trg}} \cdot \mathrm{IS}^{-1} \\ p^{\text {nor }}, & \text { otherwise. }\end{cases}
$$

Thus, the frequency of price change will be endogenous. A shop will change its posted price almost certainly twice a year, when its wage is changed and when the tax rate $\tau$ changes, because in both cases its normal price will change. Beyond that, it will only change the price when its inventory-tosales ratio passes one of the critical thresholds IS and 1/IS. When the ratio rises above the upper threshold, the shop cuts its price by the factor $\delta_{p}$. When the ratio falls below the lower threshold, it raises its price by the factor $1 / \delta_{p}$.

\subsection{Information and expectations}

Public information. It follows from the preceding description of the interaction protocol in our model that every agent is always fully informed of the following public variables: last week's economy-wide average wage rate $W$; the most recently computed price level $P$; the current one-week interest rate on government bonds $i_{w}$; the central bank's weekly inflation target $\pi_{w}^{*}$; the technology of operating a shop, including the cost parameters $S$ and $F$; the ad valorem sales tax rate $\tau$; the capitalization factor $V$ computed by the central bank; and the firesale price $P_{f}$.

Private information. In addition to this public information that every agent knows, every person always knows the values of: his own holdings of money, deposits, and legacy capital; the inventory, fixed capital, and bank loan of his shop if he is a shop owner; the identity and type of any shop with which he has a trading relationship; the identity, currently posted loan, deposit interest rates, and

\footnotetext{
${ }^{16}$ In computing this expression, we use the maximum of $\overline{x^{\text {pot }}}$ and the shop's fixed cost $F$ to avoid division by zero when potential employment falls to zero.
} 
haircut price of his bank; and his bank's equity and required capital if he is a bank owner. Moreover, we assume that every person always remembers his permanent income $Y^{p}$, which is updated every period during the financial market stage, as well as his effective wage and the effective retail prices for his primary and secondary consumption goods.

Expectations. As in most macroeconomic models, expectations of inflation and of interest rates play an important role in people's demand behavior. We suppose that the central bank plays a key role in anchoring these expectations, and that expectations play a benign role in aggregate fluctuations. Specifically, as described in Section 4.9, when shops set wages they expect inflation to proceed over the course of the contract period at a steady rate equal to the central bank's inflation target $\pi^{*}$.

In addition, from time to time, people want to estimate the current or future value of some variable (wage, price, or income) knowing only what it was last period. In those cases, they simply project the last known value into the future, assuming a constant weekly rate of inflation equal to $\pi_{w}^{*}=\left(1+\pi^{*}\right)^{1 / 48}-1$.

The other place where inflation expectations are critical is in the formation of household expenditure plans. In this case, we suppose again that households rely on the central bank for making forecasts, in the form of the capitalization factor $V$ computed from the central bank's projections.

\section{The workings of the model}

\subsection{Equilibrium with price flexibility and no shocks}

As the preceding discussion has made clear, all shocks in this economy are individual shocks. Unlike in the standard New Keynesian framework, we have postulated no exogenous shock process impinging on aggregate productivity, price adjustment, aggregate demand, monetary policy, or fiscal policy. Nevertheless, the individual shocks that cause matches to break up and shops to enter or leave particular markets do have aggregate consequences because there is only a finite number of agents. So, in general the economy will not settle down to a deterministic steady state unless we turn off these shocks. If we do turn off all shocks, there is a deterministic equilibrium that the economy would stay in if left undisturbed by entry and breakups (i.e., if $\theta=\delta=0$ ), with wages being adjusted each week $(\Delta=1)$. This equilibrium will serve as an initial position for all the experiments we perform on the model below, and a brief description of it helps to illustrate the workings of the model.

The equilibrium is one in which all the potential gains from trade are realized. Each person is matched with one employer and two stores. There are $n$ shops, one trading in each of the $n$ goods. To preserve symmetry across goods, we suppose that each good is the primary consumption good for exactly one shop owner. Each shop begins each week with actual, potential, and target input all equal to $n-2$, which is the number of suppliers of each good, and with actual and target sales 
equal to inventory holdings equal to actual output: $n-2-F$. Thus, the economy's total output equals full capacity: $y^{*}=n(n-2-F)$.

Each shop begins each week with a common wage rate equal to $W=\left(1+\pi_{w}^{*}\right) W_{0}$, where $W_{0}$ was the common wage rate last week, and with a retail price equal to $P=(1+\bar{\mu}) W /(1-\tau)$, where the tax rate $\tau$ equals

$$
\tau^{*}=1-\left(1+\pi_{w}^{*}\right)\left(1-48 \rho_{w} b^{*}\right) \cdot\left(1-\pi_{w}^{*} \frac{n-3}{(n-2-F)(1+\bar{\mu})}\right)^{-1} .
$$

As mentioned earlier in Section 4.7, this is the tax rate that leaves the government's real debt-toGDP ratio undisturbed in this equilibrium. We are assuming that all markups in this equilibrium are equal to the average $\bar{\mu}$.

In this no-shock equilibrium there are no bank loans outstanding, so banks are just conduits, converting deposits into government bonds. The initial outstanding stock of bonds is

$$
B=b^{*}\left(1+i_{w}\right) 48 y^{*} P_{0}
$$

where $P_{0}=P /\left(1+\pi_{w}^{*}\right)$ is last week's price level. These bonds are held equally by all banks, and each non-bank-owning person holds the amount $B / N$ of bank deposits. The weekly interest rate $i_{w}$ is given by

$$
1+i_{w}=\left(1+\rho_{w}\right)\left(1+\pi_{w}^{*}\right)
$$

The money supply at the start of the week is

$$
M=W_{0}(N-n)+(1-\tau) P_{0} y^{*}
$$

which is the sum of all wage receipts of people not owning a shop, and all sales receipts (ex taxes) of shop owners, from last period.

Each person starts the period with an effective wage equal to $W_{0}$, and with effective retail prices for both consumption goods equal to $P_{0}$. The owner of each shop starts with a permanent income equal to last week's profit

$$
\Pi=\left[\left(\bar{\mu}-i_{w}\right)(n-2-F)-\left(1+i_{w}\right)(F-1)\right] W_{0},
$$

and with money holding equal to last week's revenue $(1-\tau) P_{0}(n-2-F)$. Each person not owning a shop begins with money holding equal to permanent income, which in turn is equal to last period's wage income $W_{0}$.

No one holds any legacy capital, no banks hold seized capital, and the firesale queues are all empty. Banks hold no reserves, so each bank's equity is its share of the government debt minus its customers' deposits, which amounts to $B / N$. 
The initial history is one in which the output gap has been equal to zero for the past 12 months and inflation has equaled its target rate for the past 12 months. The central bank's real interest target is $r^{*}=\rho$, and its estimate of $\log$ potential GDP is $\tilde{y}_{0}=\ln \left(y^{*}\right)$. Its latest published capitalization factor is

$$
V=\frac{1}{1+\pi_{w}^{*}} \cdot \frac{1}{\rho_{w}} .
$$

It is straightforward to verify that this configuration will repeat itself indefinitely, with all nominal magnitudes - money and bond holdings, actual and effective wages and prices, and permanent incomes - rising each week at the constant rate $\pi_{w}^{*}$, provided that the setup cost $F$ is small enough that shops always pass the profitability test during the exit stage, which indeed it is in the baseline calibration described in Section 6 below. ${ }^{17}$

\subsection{Entry, exit, and systemic performance}

As we shall see below, on average, the economy is able to achieve about 93 percent of the capacity GDP attained in the no-shock equilibrium. GDP goes down whenever a shop that was satisfying some consumers goes out of business or a customer loses a store because of a random breakup. GDP also goes down whenever a new shop enters and diverts workers from old shops that were satisfying some customers, because some of these workers' efforts will be used up in deferring the fixed cost of the new shop rather than producing goods that can be eaten by customers of the old shop.

These events that reduce GDP are constantly being offset to some degree by the entry of new shops that are able to satisfy customers in markets where there had previously been no viable shop, and by the exit of shops that were using up fixed costs but not producing enough to satisfy their customers. Thus, both entry and exit are critical to the system's ability to approximate fullcapacity utilization. However, although entry of new shops is useful in markets where there are no incumbents, or where the incumbents are not hiring all the potential workers because of layoffs or because of financial problems that prevent them from meeting their payroll, entry can be harmful (to the level of real GDP) in cases where incumbent shops were hiring most of the potential workers and satisfying most of the potential customers. Likewise, although exit is important in cases where the shop has ceased to play an active intermediation role, whether because of financial difficulties, a surfeit of inventories, or a too high markup, exit can also be very harmful in cases where the incumbent was previously doing well, because it can cascade across markets causing a cumulative loss of output (see Howitt, 2006).

Banks have two influences on this cumulative process of shop failures. One is the familiar "lending channel" of the financial accelerator. That is, when a shop fails, this may cause its bank to get into trouble, or at least to get close to being in trouble, because some of its loans may go bad. This will cause it to lend less readily, either by reducing its probability of approving credit

\footnotetext{
${ }^{17}$ In our baseline calibration $F=3.5$, whereas the critical value $F^{*}$ at which the profitability test fails is 63 .
} 
line applications or, in the extreme case, by having the government forbid it from making any new loans. This makes it more likely that other firms will fail for lack of finance.

The other influence that banks have is a more salutary one of ameliorating the cumulative process. That is, the cascade of shop failures will be dampened if another shop quickly replaces each failed shop. This is more likely to happen when banks are willing to lend because bank lending makes it easier to pass the financial viability test at the entry stage each week.

As we shall see, it seems that the latter effect of banks, facilitating entry, appears to play a more important role in our model, especially when the system is far below full-capacity utilization, than the more traditional accelerator role, in the sense that banks dampen shocks and allow the economy to achieve on average a higher degree of capacity utilization.

\section{Calibration}

Although the model has many agents, we have imposed a great deal of ex ante symmetry. We have done this partly to be able to fully characterize the no-shock equilibrium that serves as a reference point, which will facilitate our analysis of what is generating the experimental results, and also partly to keep the number of parameters small enough to calibrate them to U.S. economic data. This section describes our calibration procedure.

There are a total of 33 parameters, which we have categorized as personal parameters, shop parameters, bank parameters, and government policy parameters. These are listed in Table 1 along with their assigned values and the six-letter codes to be used further below in the sensitivity analysis in Section 9.

Our calibration of these parameters took place at three different levels. At the first level, one subset of parameter values was chosen to match their empirical counterparts in the U.S. data and/or the values used in previous studies. At the second level, the values of other parameters were chosen so as to be internally consistent with median outcomes across simulations. At the third level, the values of the remaining parameters, for which we could find no convenient empirical counterparts, were chosen to make their median outcomes across simulations (loosely) match certain properties of the U.S. data.

\subsection{First level of calibration}

\subsubsection{Personal parameters}

We set the annual rate of time preference $\rho$ equal to 0.04 as is standard in the real business cycle literature. We chose the demand parameter $\varepsilon$ to equal 7 , which implies that the elasticity of demand facing each shop would be $1+\varepsilon / 2=4.5$ in a no-shock equilibrium with all shops charging the same price. This lies in the range of values typically found in New Keynesian DSGE models. ${ }^{18}$ However,

\footnotetext{
${ }^{18}$ Demand elasticity is set equal to 3 in Midrigan (2011), 4 in Nakamura and Steinsson (2010), and 7 in Golosov and Lucas (2007). The benchmark calibration in Burstein and Hellwig (2008) yields an elasticity of 4.4.
} 
TABLE 1: The calibrated parameters of the model

\begin{tabular}{|c|c|c|c|}
\hline \multicolumn{4}{|c|}{ Personal parameters } \\
\hline$\rho$ & Rate of time preference (annual) & 0.04 & TMPRFY \\
\hline$\varepsilon$ & Demand parameter & 7.0 & DMDELS \\
\hline$\delta$ & Quit rate (weekly) & 0.00075 & BRKFRC \\
\hline$\lambda_{p}$ & Permanent income adjustment speed (weekly) & 0.4 & INCSPD \\
\hline$\sigma$ & Job search probability & 0.5 & SRCHPP \\
\hline$\theta$ & Frequency of innovation (weekly) & 100 & INFREQ \\
\hline \multicolumn{4}{|c|}{ Shop parameters } \\
\hline$\Delta$ & Length of the contract period (in weeks) & 48 & CNTPRD \\
\hline$F$ & Fixed cost (weekly) & 3.5 & FXDCST \\
\hline$\lambda_{I}$ & Inventory adjustment speed (weekly) & 0.16 & INVSPD \\
\hline$\beta$ & Wage adjustment coefficient (annual) & 0.3 & WAGSPD \\
\hline $\bar{\mu}$ & Average percentage markup over variable costs & 0.138 & MARKUP \\
\hline$\phi$ & Failure rate of unprofitable shops (weekly) & 0.011 & FAILRT \\
\hline$S$ & Setup cost & 15 & SETUPC \\
\hline IS & Critical inventory-to-sales ratio & 3.0 & TRIGGR \\
\hline$\delta_{p}$ & Size of price cut (old price/new price) & 1.017 & PDELTA \\
\hline \multicolumn{4}{|c|}{ Bank parameters } \\
\hline$s$ & Loan spread (annual) & 0.0175 & SPREAD \\
\hline$C_{b}$ & Cost of foreclosure & 0.1 & BKRCST \\
\hline$l$ & Slope of loan approval schedule & 9 & PSLOPE \\
\hline \multicolumn{4}{|c|}{ Government policy parameters } \\
\hline & Fiscal policy & & \\
\hline$b^{*}$ & Target debt-to-GDP ratio & 0.33 & BNDINC \\
\hline$\lambda_{\tau}$ & $\begin{array}{l}\text { Fiscal adjustment speed (annual) } \\
\text { Monetary policy }\end{array}$ & 0.054 & FSCSPD \\
\hline$\widehat{\lambda}_{\pi 0}$ & Inflation autocorrelation coefficient (initial estimate) & 0.29 & INFCOR \\
\hline$\widehat{\lambda}_{y 0}$ & Output autocorrelation coefficient (initial estimate) & 0.66 & GAPCOR \\
\hline$\gamma_{\pi}$ & Inflation coefficient in Taylor rule & 1.5 & INFTYR \\
\hline$\gamma_{y}$ & Output gap coefficient in Taylor rule & 0.5 & GAPTYR \\
\hline$\pi^{*}$ & Target inflation rate (annual) & 0.03 & PITRGY \\
\hline$r_{0}^{*}$ & Initial target real interest rate (annual) & 0.032 & RRTTRG \\
\hline$\tilde{y}_{0}$ & Initial estimate of potential output & 7.6 & GAPTRG \\
\hline$\eta_{r}$ & Adjustment speed of evolving real rate target & 0.0075 & ADJRRT \\
\hline$T_{\mathrm{cb}}$ & $\begin{array}{l}\text { Number of years before CB's learning begins } \\
\text { Bank regulation }\end{array}$ & 10 & LRNLAG \\
\hline$\kappa$ & Required capital adequacy ratio & 0.08 & CARATE \\
\hline$s_{d}$ & Premium on CB's discount rate (annual) & 0.005 & DISCPR \\
\hline$m$ & Number of banks & 5 & NBANKS \\
\hline$h$ & Loan-to-value ratio & 0.5 & LVALRT \\
\hline
\end{tabular}


the elasticity of demand faced by a shop out of equilibrium, when he has rivals selling the identical good, will be larger than 4.5 because raising the retail price may induce a loss of all demand from any customer that finds another shop during the matching process. ${ }^{19}$

\subsubsection{Shop parameters}

Smets and Wouters (2007) estimate the average duration of wage contracts in the U.S. to be about a year. This is consistent with evidence from other studies cited in Amano et al. (2009, section 4). Accordingly, we set the length of the wage contract period $\Delta$ to 48 weeks, which in our model is one year.

Estimates of the degree of returns to scale in the U.S. economy vary from 0 to about 30 percent. It is commonly measured as the ratio of average to marginal cost (minus unity). In our model, the typical shop in a steady state with input equal to $x$ and sales equal to $x-F$ would thus have a degree of returns to scale equal to

$$
\frac{A C}{M C}-1=\frac{W x /(x-F)}{W}-1=\frac{F}{x-F} .
$$

If the economy was operating with a 6 percent average unemployment rate, then the typical shop would have $x=0.94 \cdot(n-2)=45.12$, so by setting the fixed cost $F$ equal to 3.5 we get a typical degree of returns to scale equal to 8.4 percent.

The inventory adjustment speed $\lambda_{I}=0.16$ corresponds to the estimate by Durlauf and Maccini (1995) of a monthly adjustment speed equal to $1-(1-0.16)^{4} \approx 0.5$.

Roberts (1995) estimated aggregate expectations-augmented Phillips relations with a coefficient on detrended output between 0.25 and 0.334 using annual data. A linear approximation to our wage-adjustment equation yields the same relation at the firm level if we assume that the actual/capacity output ratio is proportional to the target/potential input ratio. Accordingly, we chose $\beta=0.3$ to lie near the midpoint of Roberts' range of estimates.

\subsubsection{Bank parameters}

The value of the normal annual loan spread $s$ was set equal to 0.0175 , which is the average spread between lending and deposit rates for all commercial and industrial loans during the period 19862008. This figure comes from the Survey of Business Lending Terms conducted by the Federal Reserve.

We set the cost of foreclosure equal to 0.1 , which falls in the 2 percent to 20 percent range suggested by Bris et al. (2006).

\footnotetext{
${ }^{19}$ This is another consequence of our decision to model goods markets as "customer markets" after Phelps and Winter (1970).
} 


\subsubsection{Government Policy parameters}

Fiscal policy. The target debt-to-GDP ratio $b^{*}$ was set equal to 0.33 because this is the average ratio of federal marketable debt to GDP in the U.S. between 1969 and 2005. The fiscal adjustment speed $\lambda_{\tau}$ was estimated at 0.054 by Bohn (1998).

Monetary policy. The initial estimates of the autocorrelation factors $\widehat{\lambda}_{\pi 0}$ and $\widehat{\lambda}_{y 0}$ were taken from estimates of univariate AR(1) processes on inflation and on (linearly detrended) log per-capita GDP using annual data for the U.S. over the 1984-2006 period. The coefficients $\gamma_{\pi}$ and $\gamma_{y}$ are Taylor's original specification. We took the inflation target $\pi^{*}$ to equal 3 percent, which is the average in the U.S. over the 1984-2006 period.

Bank regulation. We set the required capital adequacy ratio $\kappa$ equal to 0.08 , which corresponds to the Basel I capital accord. The CB's discount rate premium $s_{d}$ is set to 0.005 , which approximates the typical spread of the Federal Reserve's primary credit discount rate over the federal funds rate.

\subsection{Second level of calibration}

\subsubsection{Government targets - finessing Wicksell}

The two government policy targets - the target real interest rate $r^{*}$ and log potential output $\tilde{y}-$ are chosen adaptively by the government. We chose the initial value of $r^{*}$ to be 0.032 , which is close to the steady-state value, on average across simulations, in our baseline calibration. Likewise, we choose the initial value of $\tilde{y}_{0}$ to be 7.6 , which is its median value ${ }^{20}$ across simulation runs in our calibration exercise. Since government adaptation was relatively quick, and its learning period was quite long, our results were not sensitive to the choice of these initial values.

Note that our procedure of having the government estimate $r^{*}$ and $\tilde{y}$ forces it to deal with the danger that writers from Wicksell to Friedman and up through Orphanides have warned of - the danger that no one knows the economy's natural rate of interest or potential output, and hence that controlling the rate of interest to the neglect of the money supply risks aggravating volatility or even engendering cumulative inflation.

\subsubsection{Markups and the Lucas Critique}

In early trials with the model, we assumed that all shops applied the same markup. But we found that the results of many experiments were highly sensitive to the assumed size of the markup. Awareness of the Lucas critique prompted us to revise the model in favor of the current assumption, namely that each shop picks its markup at birth. This variant allows the economy-wide average markup to respond endogenously to the policy environment, through the evolutionary selection mechanism implicit in the exit process. We chose the mean of the distribution from which markups

\footnotetext{
${ }^{20}$ This corresponds to the logarithmic output gap (between capacity GDP and actual GDP) of 0.074 reported in Table 3.
} 
TABLE 2: U.S. data vs. median outcomes in the model

\begin{tabular}{lcc}
\hline Variable & Data & Model \\
\hline Inflation & 3.0 & 2.9 \\
Real interest rate & 1.8 & 3.2 \\
Unemployment rate & 6.1 & 5.9 \\
Unemployment duration & 14 & 10 \\
Volatility of output gap & 2.0 to 3.2 & 2.8 \\
Volatility of inflation & 1.3 & 0.69 \\
Autocorrelation of gap & 20 to 76 & 43 \\
Autocorrelation of inflation & 16 & 19 \\
Average markup & 10 to 20 & 14 \\
Exit rate & 46 & 40 \\
Job loss rate & 0.69 & 0.59 \\
Price-change frequency & 4.0 & 4.1 \\
Annual bank failure rate & 0.51 & 0.50 \\
\hline
\end{tabular}

are drawn in the same way that we decided on the initial values of the government targets - by internal consistency. The median markup across simulation runs in our baseline calibration exercise is about 0.138 when shops choose from a distribution whose mean $\bar{\mu}$ is 0.138 .

\subsection{Third level of calibration}

This leaves 13 parameters still to be determined, namely $\phi, S$, IS, $\delta_{p}, \delta, \lambda_{p}, \sigma, \theta, l, \eta_{r}, T_{\mathrm{cb}}, m$, and $h$. These were chosen by searching (manually) for parameter values that would make the values of thirteen different indicators in our model approximate their counterparts in the U.S. data. More specifically, we ran 10,000 simulations of 60 years. Each simulation run started near the no-shock equilibrium and continued for 20 years before we started calculating the average value of each indicator variable across the remaining 40 years of that simulation. For each variable, we then computed the median across all simulation runs of these cross-year averages. The thirteen indicator variables are listed in Table 2, along with their actual values from U.S. data and their median values in our fully calibrated model.

All numbers are expressed in percentage points, except for unemployment duration, which is expressed in weeks, and price-change frequency, which is expressed in number of changes per year. The actual values from U.S. data for these thirteen indicators were determined as follows. The real annual interest rate is computed as the difference between the annual interest rate on 3-month T-bills (monthly data from the Federal Reserve) and the CPI inflation rate (monthly data from the U.S. Bureau of Labor Statistics), averaged over the period 1984-2006. Unemployment rate and duration are the averages over the period from 1969 to 2009. The volatility of the output gap is the standard deviation of linearly detrended and HP-filtered log per-capita GDP, and the volatility of inflation is the standard deviation of annual U.S. CPI inflation over the 1969-2009 period. The autocorrelations of these two variables are computed by estimating an $\operatorname{AR}(1)$ process 
over the same time period. Golosov and Lucas (2007) indicate that estimates of the percentage markup vary between 10 and 20 percent. The exit rate is the fraction of all shops found operating in a given industry in one census year that are found still operating in that industry in the next census year (five years later), which Dunne et al. (1988) report to be 46.4 percent. The job loss rate is the weekly rate of job loss that would give rise to the number reported by Hall (1995), namely that 71.8 percent of people working at a given date have been working continuously for the same employer for the past year. ${ }^{21}$ Bils and Klenow (2004) find an average price-change frequency of 16 weeks, which in our model would imply an average annual price-change frequency of 3 . However, in our model, shops will almost always change prices every time there is a change in the sales tax, which is once per year, whereas in reality sales tax changes are very infrequent. Thus, we aimed to match a price-change frequency of 4 . Finally, according to the FDIC (Historical Statistics on Banking), the average commercial bank failure rate was about 0.51 percent per year over the period from 1984 to 2006.

As Table 2 shows, we were mostly successful in mimicking the data with our 13 parameters. Specifically, our model underpredicts the duration of unemployment, the volatility of inflation, the job loss rate, and the exit rate.

\section{Simulating the model}

Each simulation run of the model is allowed to continue for $T=2880$ weeks (60 years). We repeat this for $R=10,000$ runs. Each run starts off near the flexible-price no-shock equilibrium described in Section 5.1 above. We do not start tabulating results from each run until 20 years have passed, so as to allow the system time to settle into a stochastic steady state. As Figure 1 shows, our 20-year adjustment period was indeed enough for the cross-run average values of the output gap (measured as the difference between log capacity GDP and log actual GDP), the real interest rate, and the inflation rate to become more or less constant, except for the slight downward trend in the cross-run average gap over the first half of the final 40-year period. The figure shows the average value at each year across all 10,000 runs, with the output gap measured on the left-hand axis, and the real interest rate and inflation rate on the right-hand axis.

\subsection{Normal times and bad times}

Most of the simulation runs produced time paths that exhibit strong homeostatic tendencies. However, as indicated in our introductory remarks, there are also a few "pathological" runs in which the market makers appear to have lost control of the system. This is an important nonlinear feature of the model, which seems to behave in a qualitatively different manner in bad times as compared to normal times. To convey some idea of this qualitative difference, Figure 2 depicts the actual time

\footnotetext{
${ }^{21}$ That is, $(1-\alpha){ }^{48}=0.718$ if $\alpha=0.00688$.
} 


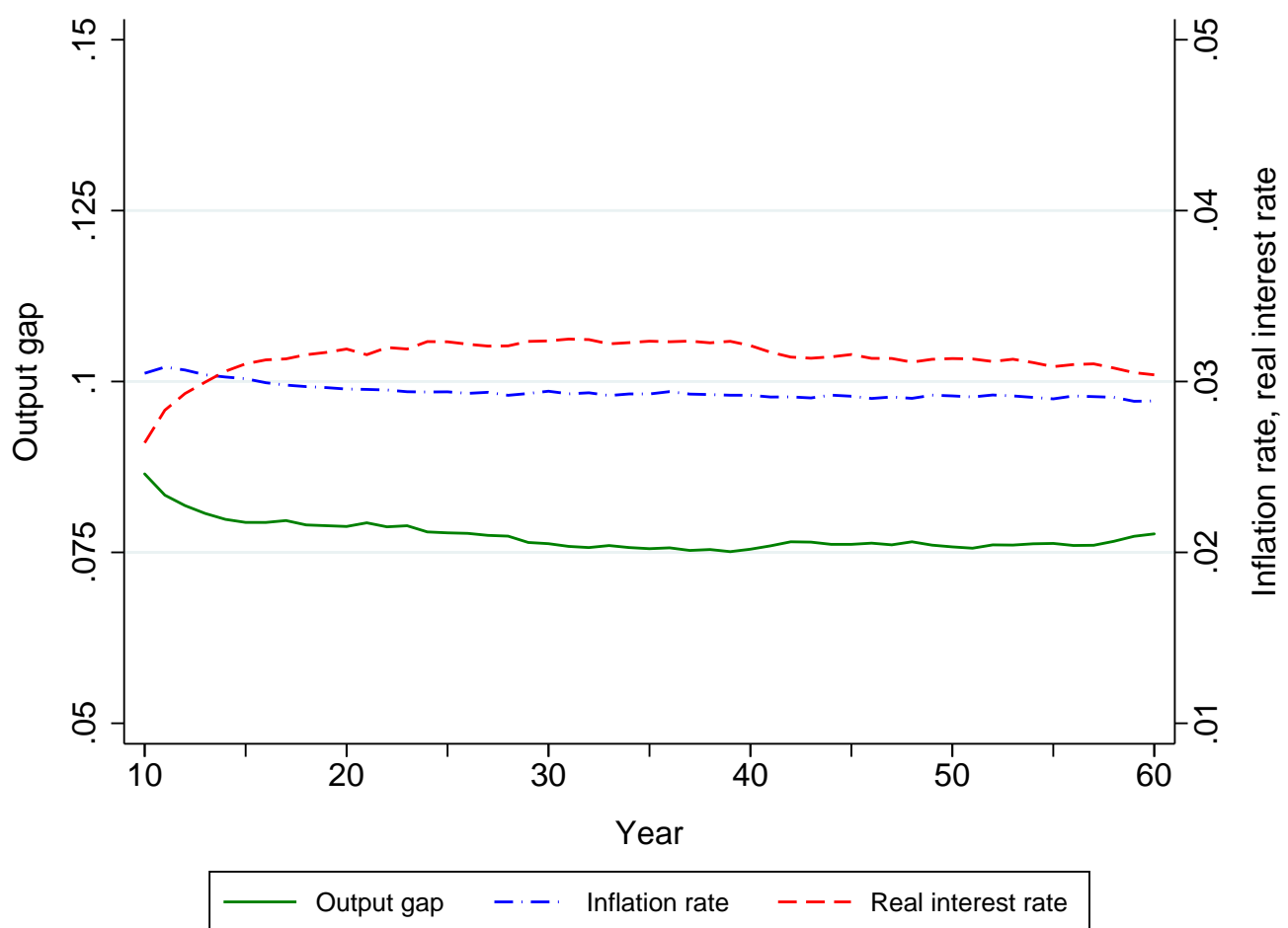

Figure 1: Time series of the cross-run averages

path of three major macroeconomic variables in one of the many "normal" runs of the system. ${ }^{22} \mathrm{~A}$ randomly chosen simulation would almost certainly depict similar characteristics. There are times when the output gap rises for a few years, but these times are soon followed by recovery. The output gap rarely exceeds 0.2 .

In contrast with these normal runs, Figure 3 illustrates what happens in some of the "worst decile" of runs, that is, in runs belonging to the first decile of the distribution across all 10,000 runs of the 40-year average output gap. Again, there are times when the output gap rises for a year or two, but beyond some point it breaches the usual upper limit of 0.2 and shows no tendency to return to anything like the cross-run average of 0.074 . Indeed, there were 4 runs out of 10,000 in which the output gap became infinite $(\mathrm{GDP}=0)$ in finite time. ${ }^{23}$ Although we have not investigated the matter in a rigorous statistical sense, we doubt that such behavior could be produced by any known linear macro model. These collapses suggest the presence of something like Leijonhufvud's (1973) "corridor;" it seems as if the economy is capable of absorbing shocks up to some limit but not beyond.

\footnotetext{
${ }^{22}$ The "rnseed" number in each figure caption indicates the initial seed value of the random number generator for the depicted run.

${ }^{23}$ We excluded these runs from the computation of the cross-run average paths shown in Figure 1.
} 


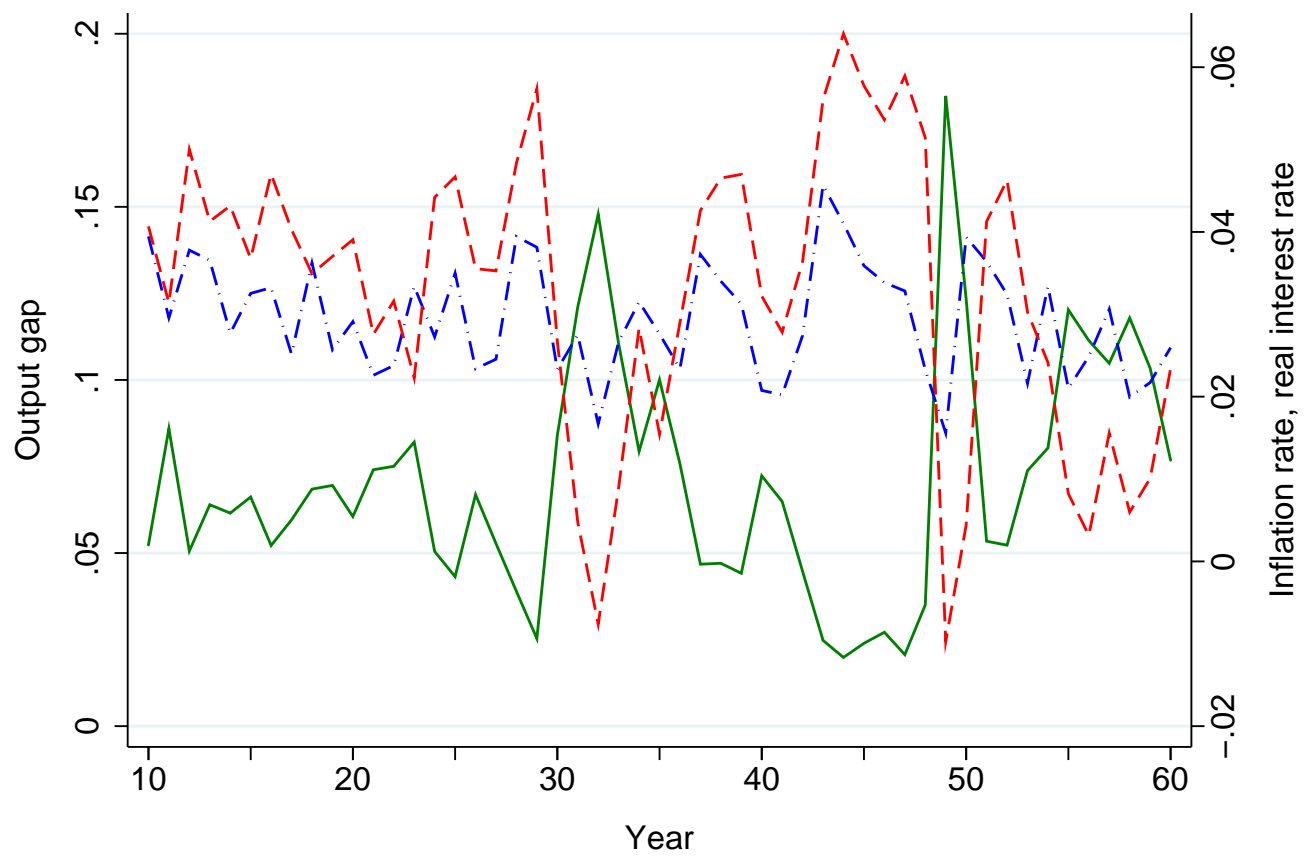

Output gap $\quad-\cdots$ Inflation rate $\quad---$ Real interest rate

Figure 2: A normal run $($ rnseed $=17)$

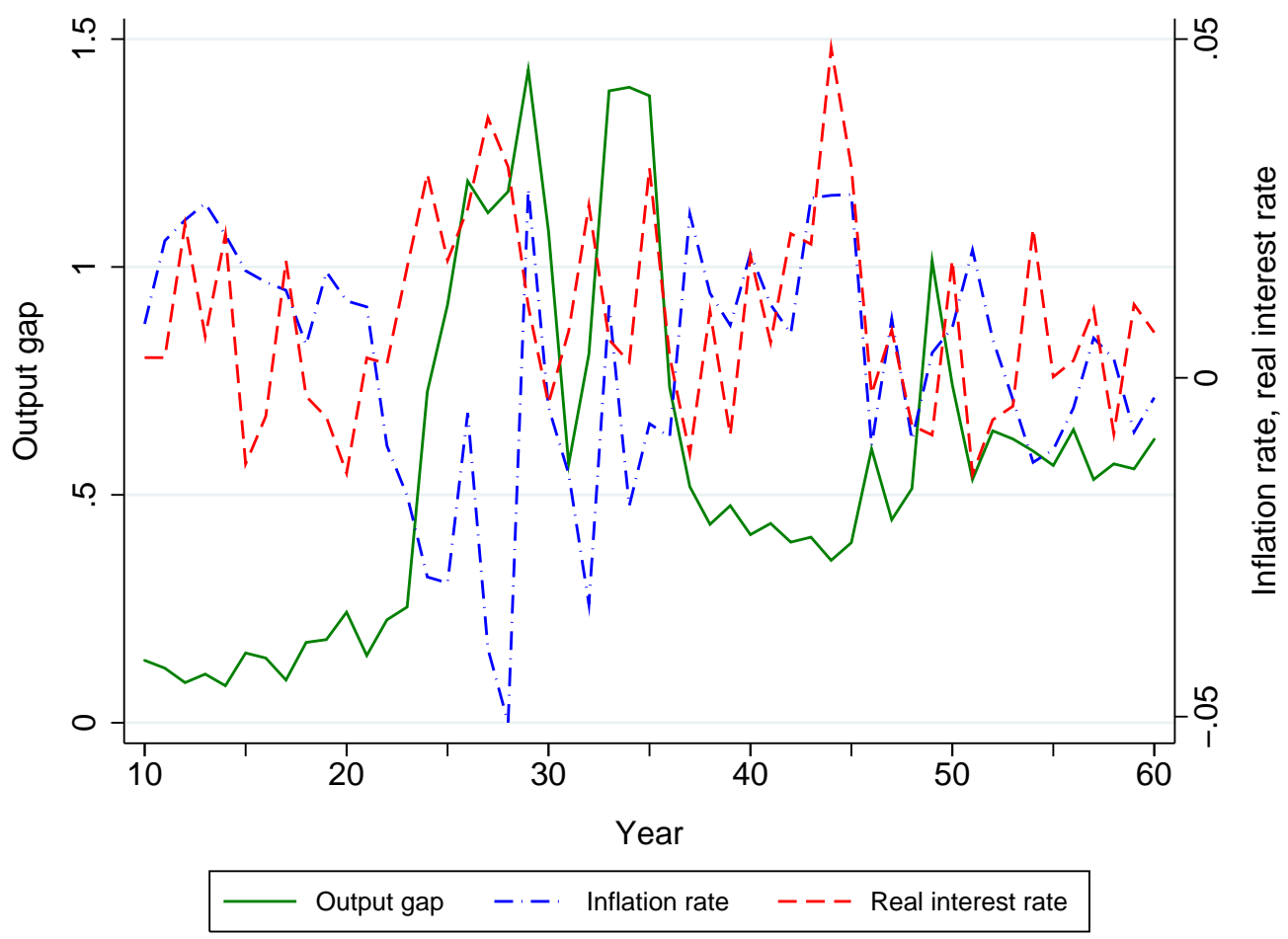

Figure 3: A collapse $($ rnseed $=5340)$ 


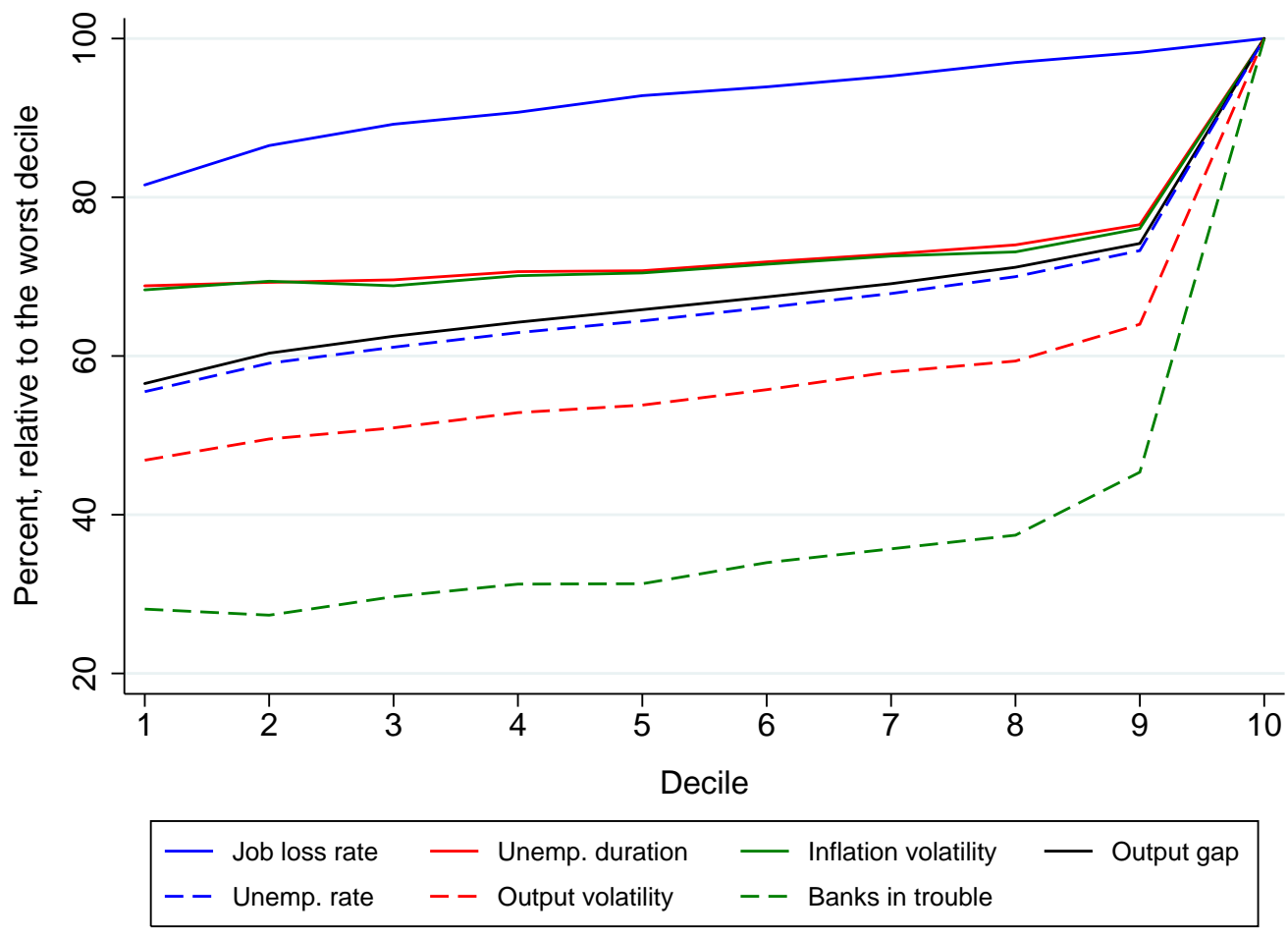

FiguRE 4: Macro performance by decile

\subsubsection{The anatomy of bad times}

Figure 4 indicates the average behavior of various macro performance measures by decile of runs, where the runs are ordered in terms of their cross-year average output gap. ${ }^{24}$ As illustrated by the figure, with the exception of the job loss rate, there is a sharp deterioration in all these measures in the tenth decile. ${ }^{25}$

To some extent, this deterioration is just what one would expect from a more standard New Keynesian DSGE model that respected the zero lower bound on nominal interest rates. ${ }^{26}$ Indeed, as Figure 5 shows, the fraction of times in which the zero lower bound is hit rises sharply from 0.035 in the ninth decile to 0.114 in the tenth.

However, there is more going on. Figure 6 reports the results of redoing the 10,000 simulation runs of our basic calibration, but allowing the nominal interest rate to be determined by the Taylor rule even when this rule would make it negative. All other behavioral rules in the model were left unchanged. Of course, this experiment begs the question of why people would aim to have their cash-in-advance constraints binding when the nominal interest rate was below zero, but it does

\footnotetext{
${ }^{24}$ Each performance measure is its mean value during the final 40 years of a run, averaged across runs specific to a given decile.

${ }^{25}$ The variables consist of those listed in Table 3, except for the rate of inflation and the incidence of bank failure. As we argue below, inflation tends to move in the opposite direction to the other indicators, while bank failures in the model are salutary events.

${ }^{26}$ See, e.g., Eggertsson and Woodford (2003) or Levin et al. (2010).
} 


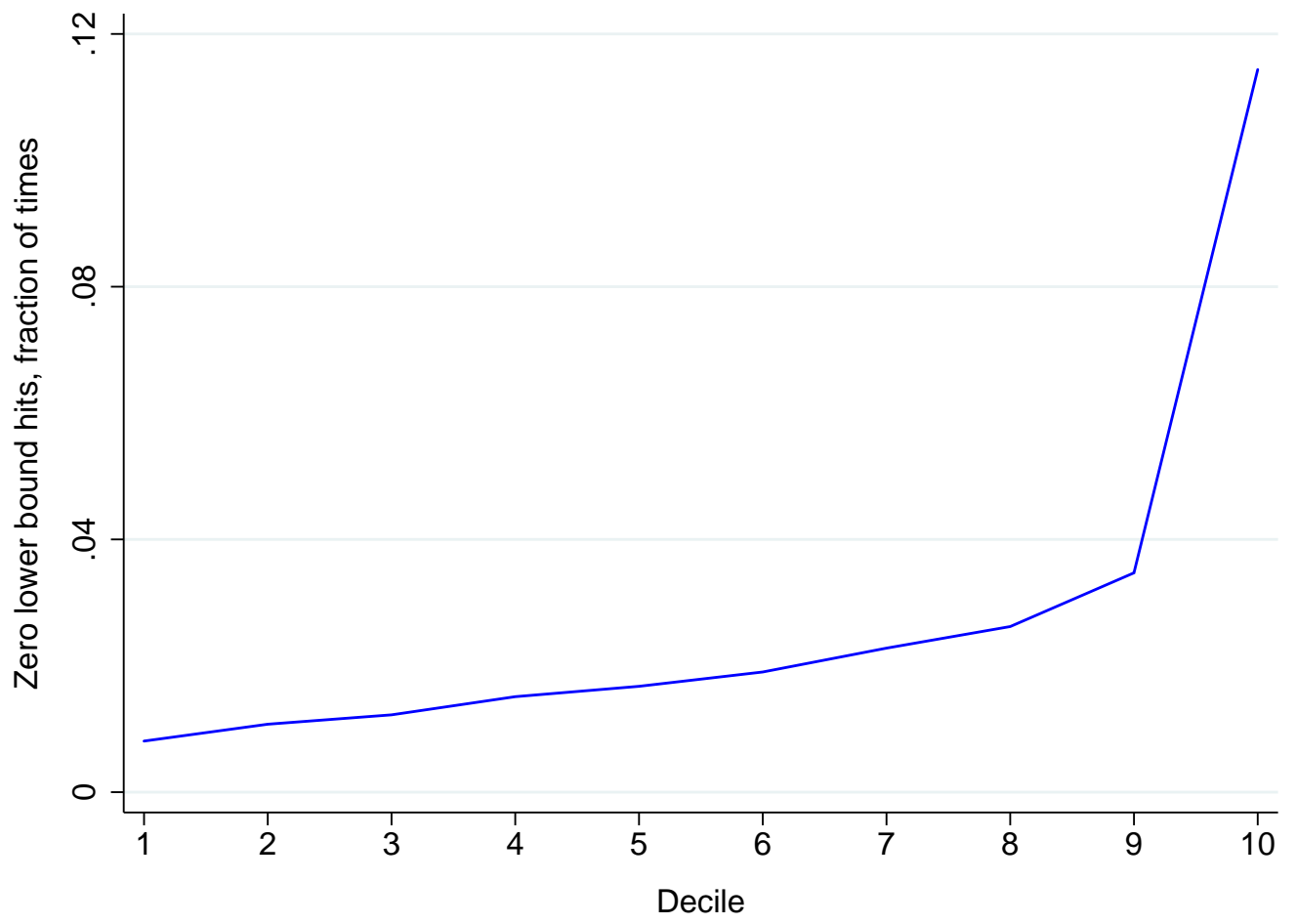

FiguRE 5: Frequency of hitting the zero lower bound

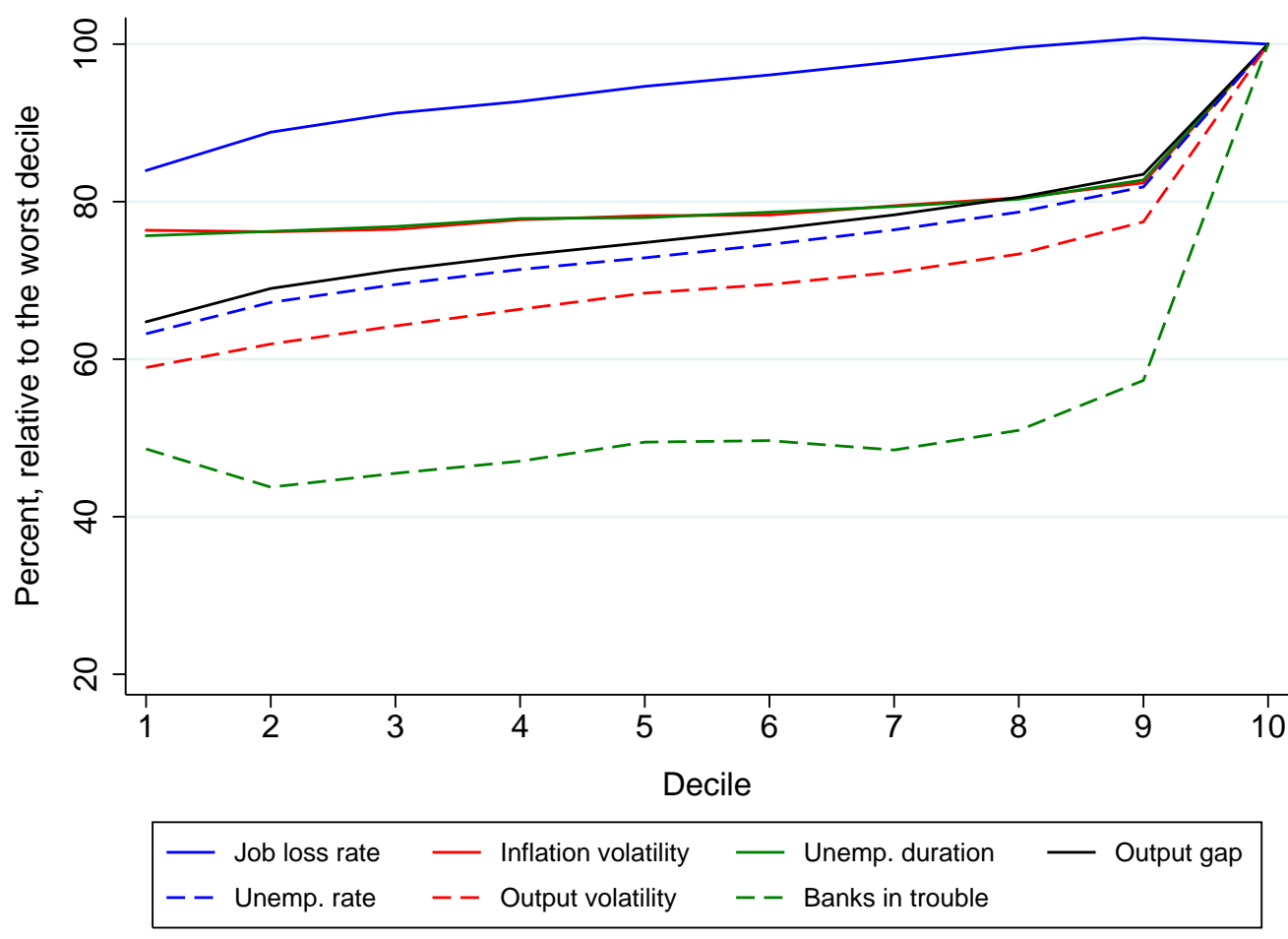

Figure 6: Decile-by-decile performance without the zero lower bound 


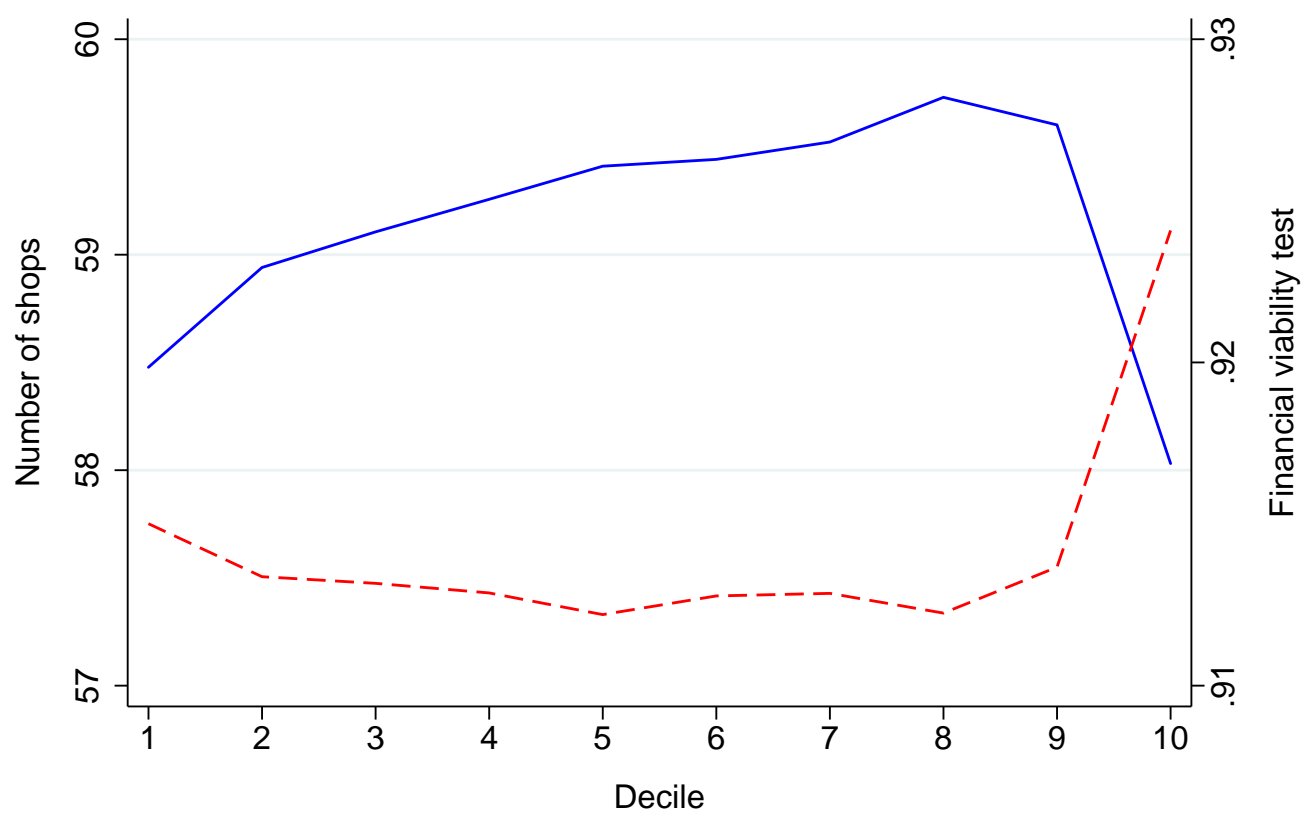

\section{Number of shops \\ - - - - Fraction of entrepreneurs failing the financial viability test}

FiguRE 7: The lending channel

nevertheless show that there is more to the results in Figure 4 than just the zero lower bound. Specifically, Figure 6 shows that, although the deterioration in macro performance is less severe than before when going from the ninth to the tenth decile of runs, there is still a kink in the relationships (except again in the job loss rate) much like before.

Instead of a more conventional zero lower bound effect, it appears that what is happening here is an amplification of recessions that works through a bank-lending channel. Specifically, when the economy experiences a bad run, banks fall into trouble. Indeed, according to both Figures 4 and 6 , the sharpest deterioration of all reported performance measures, going from the ninth to the tenth decile, is in the fraction of banks in trouble. In the baseline case, this fraction rises monotonically from decile to decile, but it rises by more than three times as much from the ninth to the tenth as it did from the first to the ninth.

Having banks in trouble means that they stop granting new loans. This discourages entry of new shops and makes exit of existing shops more likely. Figure 7 shows that, in the baseline case, this is associated with a sharp reduction in the average number of shops, and a sharp increase in the fraction of entrepreneurs who fail the financial viability test when contemplating entry, between the ninth and tenth deciles. Moreover, Figure 8 shows that these same measures of financial constraint display the same sharp deterioration beyond the ninth decile even when the zero lower bound on nominal interest rates has been suppressed. 


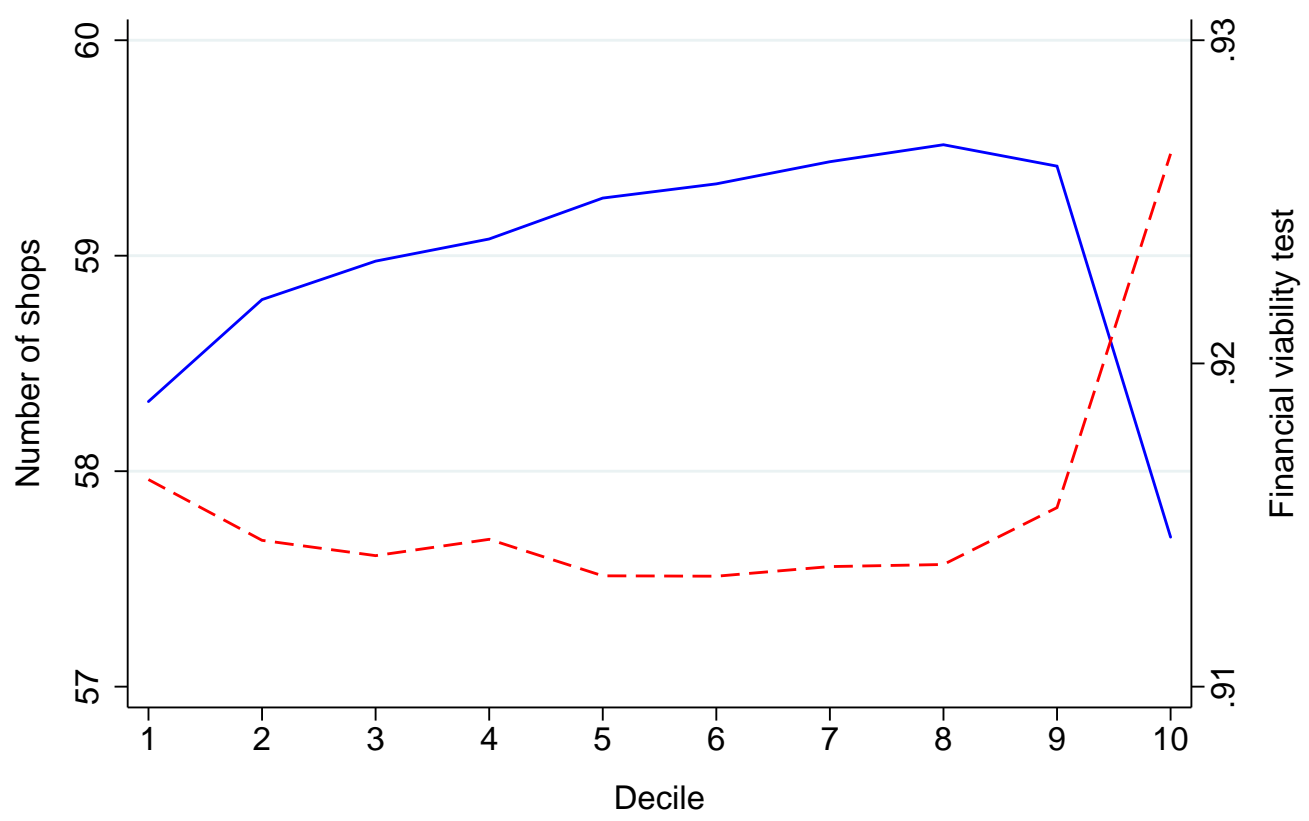

$$
\begin{aligned}
& \text { Number of shops } \\
& ----- \text { Fraction of entrepreneurs failing the financial viability test }
\end{aligned}
$$

FiguRE 8: The lending channel without the zero lower bound

\section{Analyzing the role of banks}

\subsection{Banks, no banks, and "risky" banks}

As mentioned in the introduction to the paper, our results indicate that banks do matter for macroeconomic performance, especially when times are extremely bad, and that in bad times they are especially helpful when they are riskier from the perspective of micro-prudential regulation, that is, when they have higher loan-to-value ratios and lower capital adequacy ratios.

In order to gain more insight into how banks affect median performance across runs, we performed an experiment of shutting down all banks and rerunning the simulations underlying our baseline calibration. To do this, we simply changed the banks' behavior in the financial market stage of each week so that they always imposed a credit limit of zero on all customers. This turns banks into mere conduits for the private holding of government debt. In this experiment, a bank's equity is equivalent to deposit holdings of its owner, and its risk-weighted assets (loans and seized collateral) will always be zero, so the bank will never fail and will never be in trouble.

The results of this experiment can be seen in the first two columns of Table 3, which reports the medians across simulations of the averages across years of different performance indicators. As 
TABLE 3: Median outcomes

\begin{tabular}{lccc}
\hline Variable & Banks & No banks & Risky banks \\
\hline Inflation & 2.9 & 2.5 & 3.0 \\
Output gap & 7.4 & 13 & 7.5 \\
Unemployment rate & 5.9 & 11 & 5.8 \\
Unemployment duration & 10 & 19 & 8.7 \\
Job loss rate & 0.59 & 0.68 & 0.69 \\
Volatility of output gap & 2.8 & 6.2 & 2.5 \\
Volatility of inflation & 0.69 & 1.2 & 0.61 \\
Annual bank failure rate & 0.5 & 0 & 2.5 \\
Fraction of banks in trouble & 4.6 & 0 & 1.1 \\
\hline
\end{tabular}

is evident from the table, with the exception of inflation, all indicators show a marked deterioration in median performance when banks are shut down. ${ }^{27}$

We get another measure of the importance of banks by simulating the economy's response to various exogenous shocks. Figure 9 shows the average response of the economy to a shock in which one of the five banks is forced to be in trouble for one year. Specifically, at the beginning of year 20 in the simulation (i.e., at the end of the adjustment period to a steady state), we impose on the first of the five banks the restriction that it cannot initiate new loans and cannot pay dividends to its owner, independently of its capital adequacy. We repeat this simulation 10,000 times. For a counterfactual, we perform the same 10,000 simulations, with the same sequence of seeds for the random number generator, but without the shock that forces a bank into trouble. The lower ("safe" banks) line in Figure 9 indicates the "trimmed" average difference in log GDP between the shocked and counterfactual simulations on a monthly basis for two years (24 months) following the shock. ${ }^{28}$ The effect is not huge, never exceeding one percent of the average counterfactual value, but it is persistent.

Another experiment we ran was to force a shop to fail. We did this both with and without banks. Figure 10 shows that in either case there was a humped-shape impulse response of log GDP, which is much stronger in the economy without banks (the upper curve) than in the baseline ("safe" banks) scenario. As explained by Howitt (2006), in a much simpler model based on the same foundations, the exit of a shop can cause a cumulative fall in output by depriving the shop's former suppliers of their source of income and thus endangering other shops from loss of demand. Each time a shop fails, aggregate output falls automatically by an amount equal to that shop's employment less its fixed overhead cost, unless it was already employing too few workers to cover its fixed cost. The process continues until the former employees of failed shops find new employers,

\footnotetext{
${ }^{27}$ Inflation is lower because the fact that firms always factor in the same target inflation rate $\pi^{*}$ when adjusting wages means there is a long-run tradeoff between output and inflation.

${ }^{28}$ That is, in order to avoid the noisiness of runs where either the shocked or counterfactual simulation spun out of control, we calculated, for each month, the average between the 25 th and 75 th percentile of all these differences.
} 


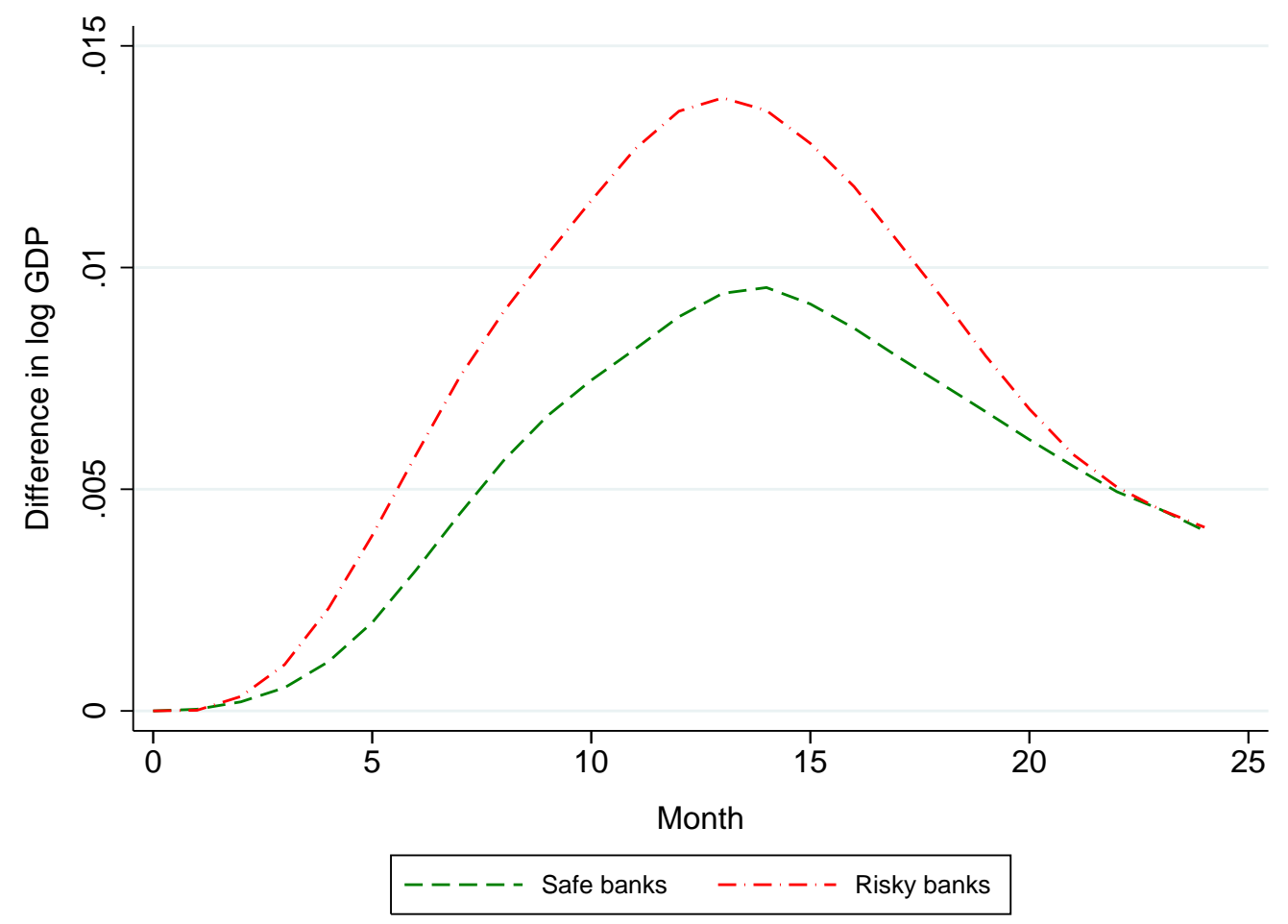

FiguRE 9: Average response to a troubled bank shock

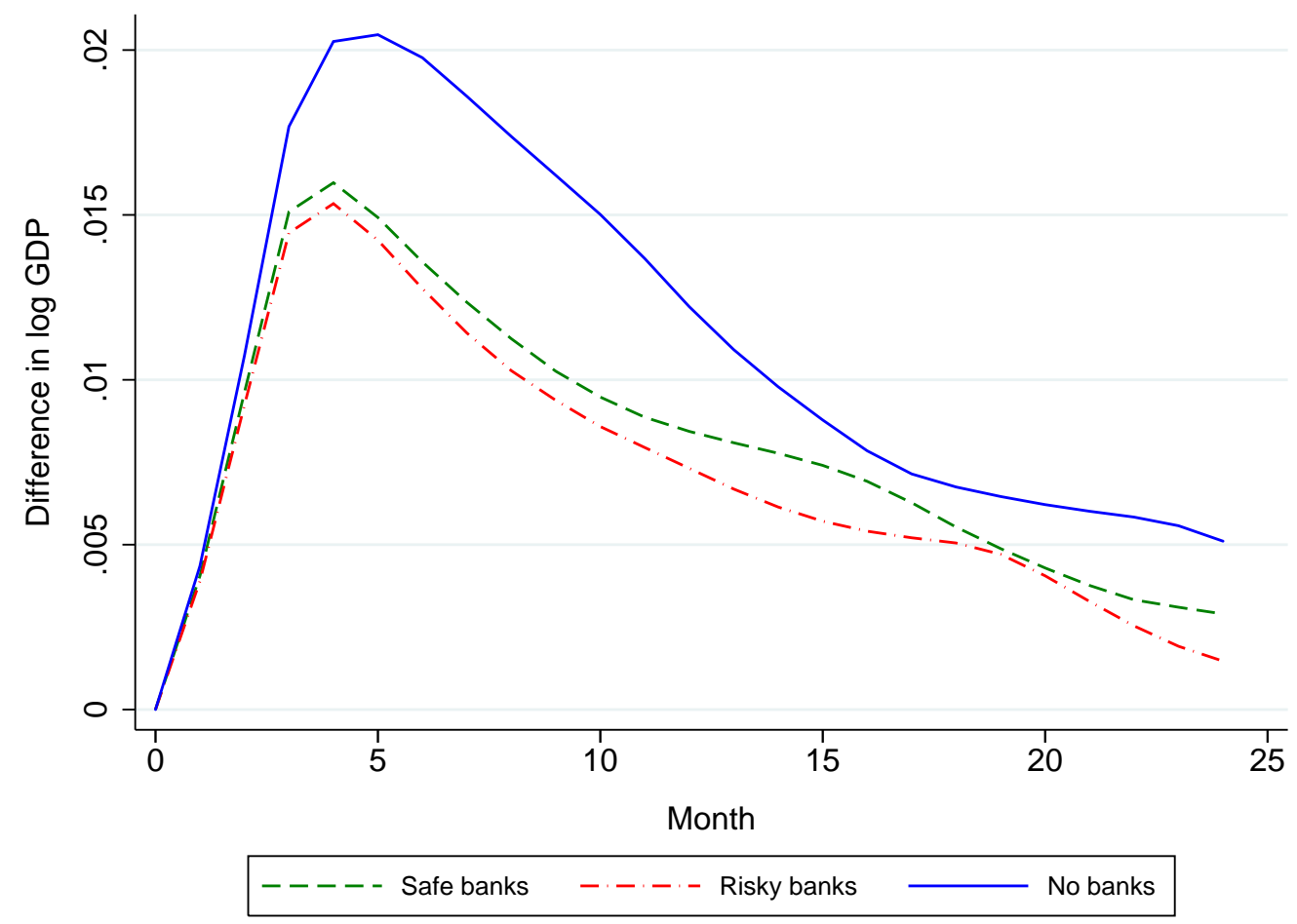

Figure 10: Average response to a shop failure 
TABLE 4: Worst-decile average outcomes

\begin{tabular}{lccc}
\hline Variable & Banks & No banks & Risky banks \\
\hline Inflation & 2.7 & 1.4 & 2.9 \\
Output gap & 11 & 44 & 9.3 \\
Unemployment rate & 8.9 & 28 & 7.2 \\
Unemployment duration & 13 & 27 & 9.9 \\
Job loss rate & 0.69 & 1.9 & 0.76 \\
Volatility of output gap & 5.2 & 23 & 3.4 \\
Volatility of inflation & 0.94 & 1.8 & 0.68 \\
Annual bank failure rate & 1.4 & 0 & 3.1 \\
Fraction of banks in trouble & 13 & 0 & 1.7 \\
\hline
\end{tabular}

and this will often require new shops to enter. As Figure 10 shows, banks play an important role in mitigating the multiplier process of cascading shop failures by facilitating new entry.

This last experiment suggests that banks should make an even bigger difference in bad times than in normal times. As we have seen, bad times are exacerbated by a loss of shops, which can be mitigated by bank lending that facilitates entry, whereas, as argued above, entry is less critical when the economy is already near a situation of full-capacity utilization. Table 4 reveals that banks do indeed make a bigger difference in bad times. It shows the average values of various performance measures across the worst decile of runs, with and without banks. In almost all cases, the difference in worst-decile averages between the two scenarios is considerably larger than the corresponding difference in medians reported in Table 3. For example, banks reduce the median unemployment rate from 11 to 5.9 percent, but they reduce the worst-decile average unemployment rate from 28 to 8.9 percent.

\subsubsection{Risky banks}

To gauge how much of a difference bank regulation will make, we consider an alternative scenario with "risky" banks, which differs from our baseline scenario with "safe" banks in two senses. First, instead of constraining its customers with a haircut price equal to the firesale price (i.e., with a loan-to-value ratio of 0.5 ), each bank in this risky scenario allows a higher loan-to-value ratio of 0.9. Second, we suppose that the required capital adequacy ratio is just 0.02 , rather than the more credit-constraining value of 0.08 .

As the third column of Table 3 indicates, macro performance under the risky scenario is roughly comparable to performance under our baseline safe scenario. Median unemployment is about the same, as is the median output gap, but volatility and unemployment duration are lower while the job loss rate is higher. As expected, the incidence of bank failures is much higher and, because trouble is defined more loosely for a risky bank, the median fraction of banks in trouble is much lower. 


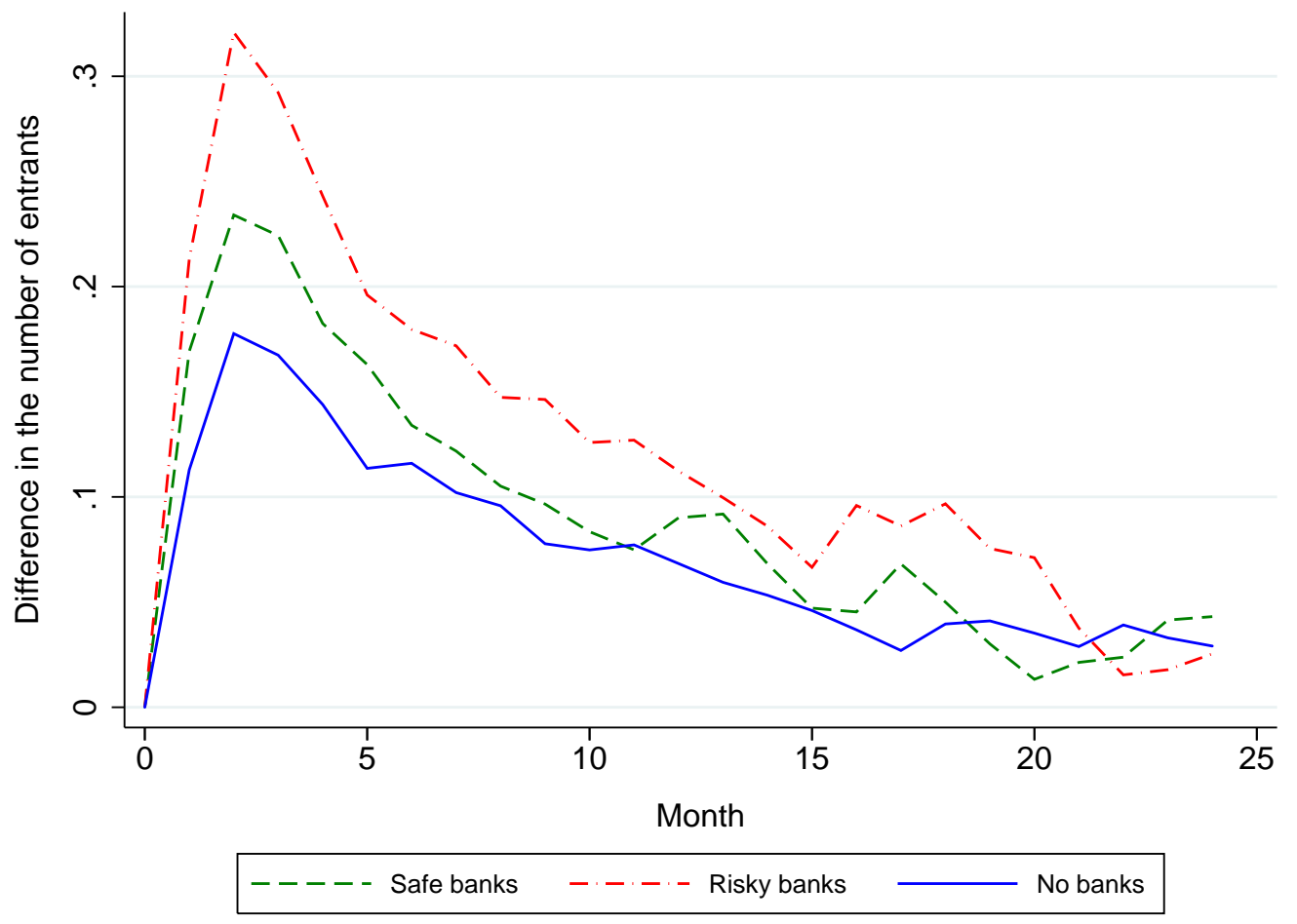

FIGURE 11: Average response of entry to a shop failure

However, as Table 4 indicates, worst-case performance is considerably better under the risky scenario than with safe banks. This is clearly because the critical role that banks play in mitigating bad times is to facilitate the entry of new shops by their willingness to lend. Risky banks will perform this role better than safe banks because their higher loan-to-value ratio makes them automatically willing to lend more when they are not in trouble. In addition, their lower capital asset ratio means that they are less often in trouble and hence less often unable to lend.

These insights are corroborated by Figure 10, which shows that the hump-shaped impulse response of GDP to a shop failure is more moderate with risky banks than with safe ones. On the other hand, Figure 9 shows that a troubled-bank shock has a larger output effect under the risky scenario, which is hardly surprising because the bank that falls into trouble cuts its lending from a larger average amount when risky than when safe. But this amplification of the troubled-bank shock is mitigated by the fact that banks are less often in trouble in the risky scenario.

\subsection{The financial accelerator and the financial stabilizer}

The fact that shop failures make banks more likely to be troubled, which in turn makes shops more likely to fail, means that in our model there is a financial accelerator that works through the banklending channel. However, the fact that the economy is less volatile and performs better on average by any measure with banks than without suggests that there must also be a "financial stabilizer" at work whose effect is more powerful than that of the financial accelerator. As explained above, this 


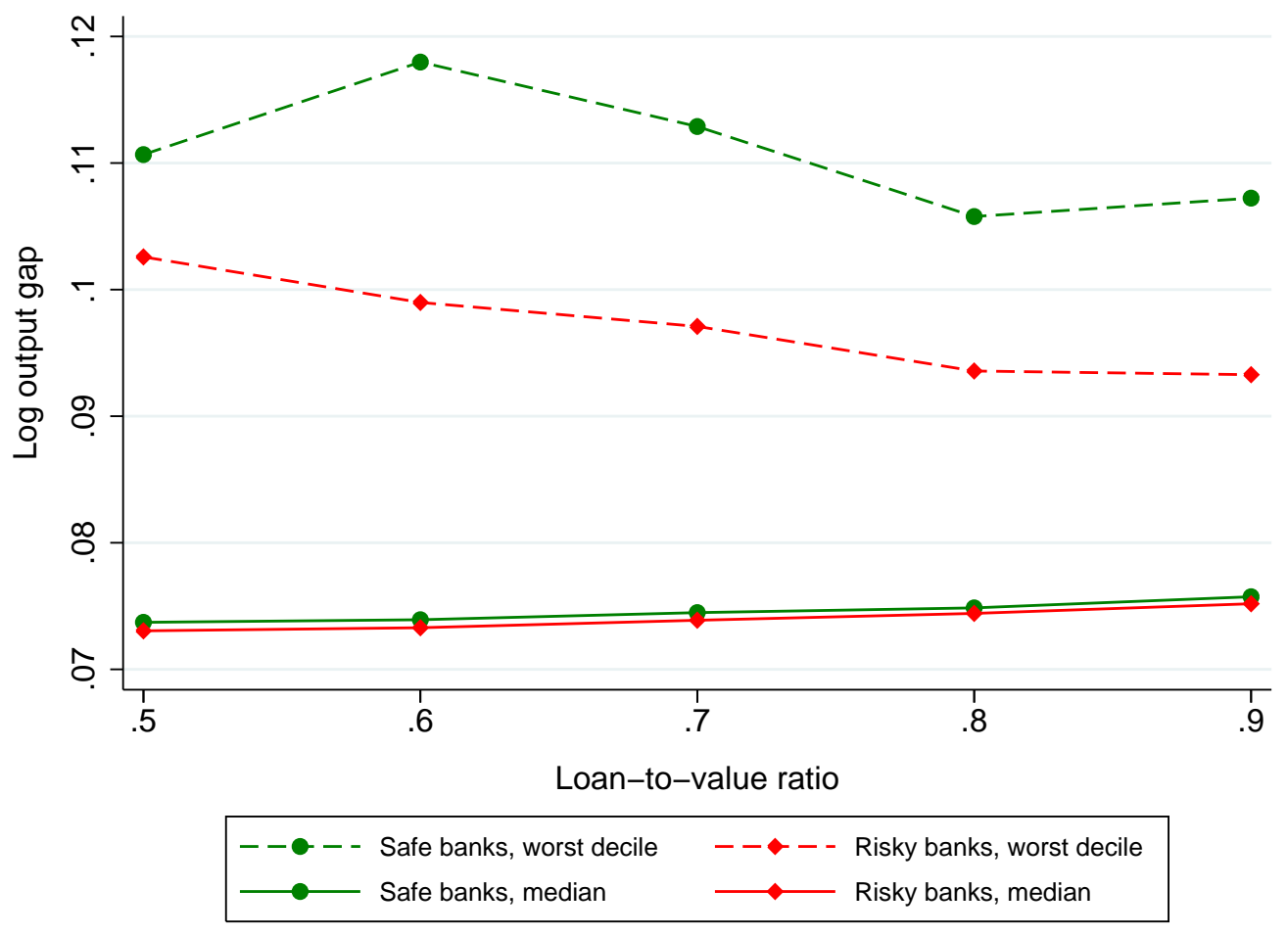

FIGURE 12: Effect of loan-to-value ratio on output gap

is because of the way banks finance entry, an effect that is shown clearly in Figure 11. This figure illustrates the average response of new entry, month by month, following a forced shop failure (in the same experiment that underlies Figure 10). In all scenarios, entry rises following a shop failure because more entrepreneurs are likely to pass the market research test when potential customers and suppliers have just lost a shop. But the response is stronger in the baseline (safe-banks) scenario than when there are no banks, and even stronger still in the risky-banks scenario.

\subsection{Policy Experiments}

Another way to see the difference between safe and risky banks is to conduct the following policy experiment. We start with the safe scenario and increase the loan-to-value ratio gradually from 0.5 to the riskier value of 0.9 , by increments of 0.1 , while maintaining the required capital adequacy ratio of 0.08 . For each of the five indicated values of the loan-to-value ratio, the model was again simulated 10,000 times. The same set of simulations was then repeated for the risky scenario, that is, with the less credit-constraining required capital adequacy ratio of 0.02 . Figure 12 shows the results of this experiment. It illustrates that the increase in the loan-to-value ratio resulted in a moderate deterioration of median performance (as measured by the output gap) under each scenario but an improvement in worst-decile average performance that is especially pronounced in the risky case. Again, this suggests that willingness to lend makes relatively little difference in normal times but helps substantially when the economy is in trouble. 


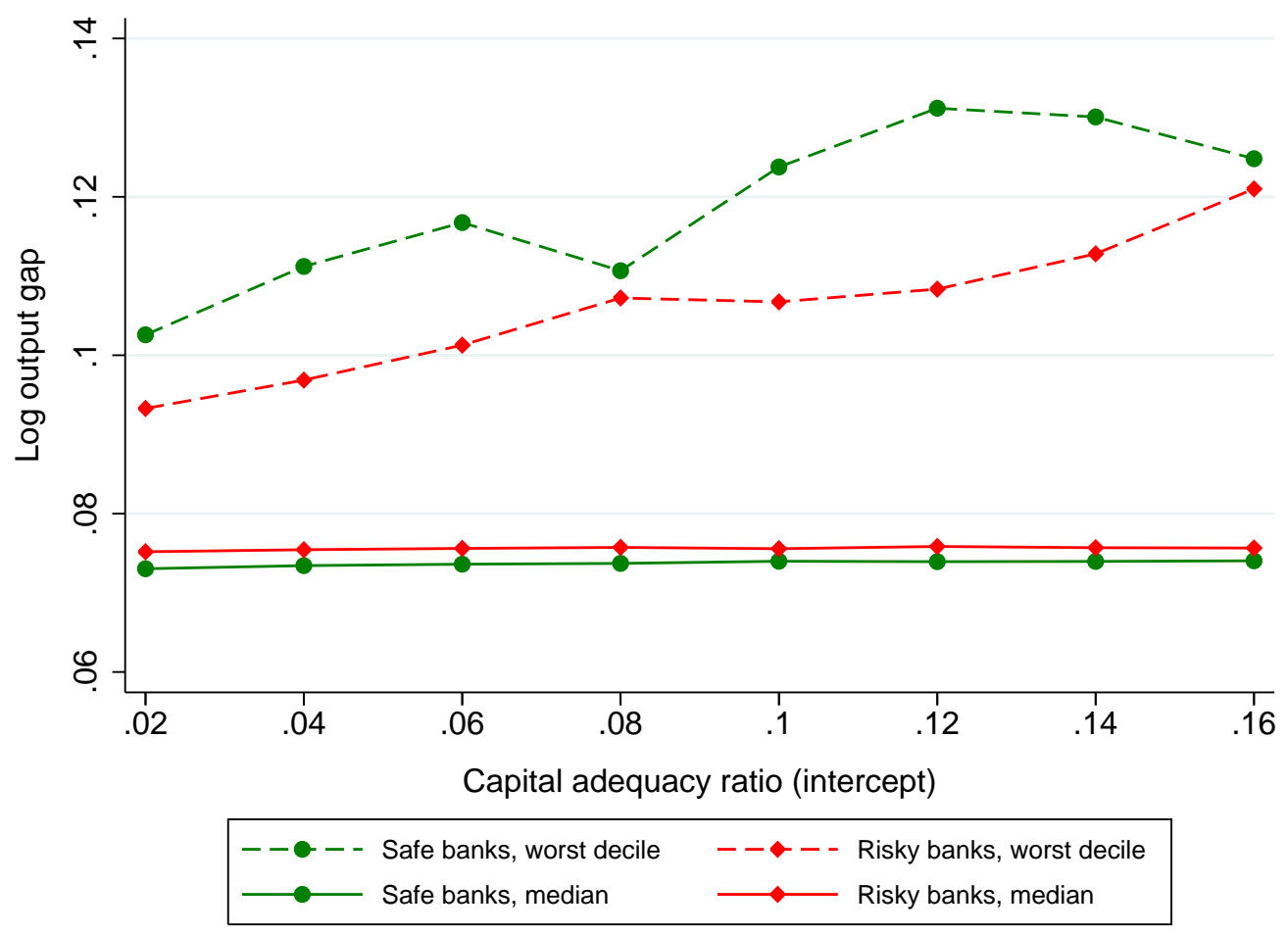

FIGURE 13: Effect of capital adequacy ratio on output gap

We also experimented with other policy interventions. Figure 13 shows the results from increasing the required capital adequacy ratio gradually from 0.02 to the more credit-constraining value of 0.16 , by increments of 0.02 , while maintaining the loan-to-value ratio at either 0.5 (for the safe scenario) or at 0.9 (for the risky scenario). Here again, the figure demonstrates that there is little effect on median performance but that worst-case performance is significantly degraded by this tightening of regulation under both scenarios.

Several commentators have called for making capital adequacy requirements procyclical under what is commonly known as macro-prudential regulation. To implement such a policy in our model, we supposed that the capital adequacy rate $\kappa$ is tied to the difference between log output and the central bank's estimate of log potential output. The adjustment is similar to that of the central bank's target interest rate and also employs a squasher. Specifically,

$$
\kappa=\bar{\kappa}+\eta_{\kappa}(y-\tilde{y}) \cdot f(y, \kappa), \quad f(y, \kappa) \equiv \frac{\bar{\kappa}}{\sqrt{\eta_{\kappa}^{2}(y-\tilde{y})^{2}+\bar{\kappa}^{2}}},
$$

where $\eta_{\kappa}$ is a fixed capital adequacy ratio adjustment parameter and $\bar{\kappa}$ is the average required capital adequacy ratio. The capital adequacy rate was adjusted according to this formula once a month, at the time of the government's interest setting decision. Figure 14 shows the results from making the capital adequacy rate increasingly procyclical by varying the adjustment parameter from 0 to 2.5. As before, we conducted simulations under both a risky scenario, that is, with an 


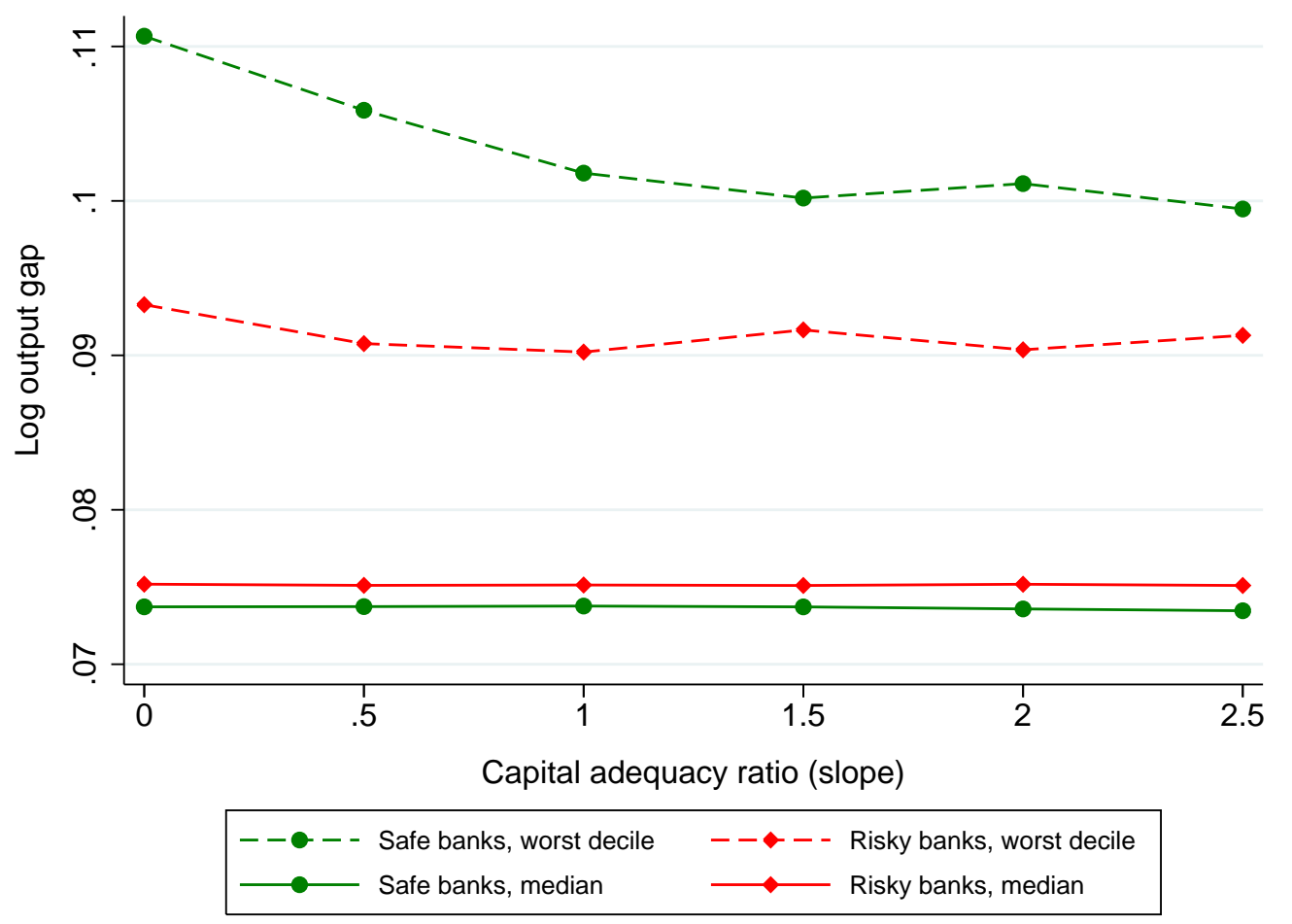

FIGURE 14: Effect of making the capital adequacy ratio procyclical

average capital adequacy ratio of 0.02 and a loan-to-value ratio of 0.9 , and a safe scenario, where the average capital adequacy ratio was set to 0.08 and the loan-to-value ratio was set to 0.5. As depicted in Figure 14, the policy has almost no effect on the median output gap or on the worst-case average performance under the risky scenario, but it does result in significantly better worst-case performance under the safe scenario.

\subsection{Making bank failure costly}

The failure of a bank in our model is a salutary event. A bank that is about to fail is almost certainly in trouble, not making any new loans, and is subsequently replaced by a new bank that can resume making new loans. Thus, one reason for our finding that risky banks result in improved macroeconomic performance is that their higher failure rate does not impinge negatively on the real economy.

One argument for believing that bank failure does in fact impair macroeconomic performance is that it may result in the loss of important information that the failing bank had regarding its customers. In particular, a new bank may require some time to get to know the customer base, and in the meantime it will not be as willing as the old bank would have been to extend credit to customers that look like poor risks on the basis of the hard information that is available to an outsider. 
To explore this possibility, we changed the model along the following lines. In each market, we designated $N^{c}$ of the $n-2$ potential shop owners as "crooks." We assumed that any bank that has been in business for at least 48 weeks knows which of the agents in its sector are crooks and which are not, but that a new bank cannot distinguish crooks from other customers until having been in business for $T^{c}$ weeks. The new bank, however, does know the fraction of total loan applications that are coming from crooks. Thus, when a bank fails, the replacement bank will charge a higher loan interest rate in order to compensate for the predictable losses generated by fraudulent loan applications.

More specifically, during the entry phase, if a crook becomes an entrepreneur, he asks his bank for a line of credit. If the loan application is granted, he takes out a loan equal to the monetary cost $S_{N}$ of his fixed capital minus his financial wealth, just like any other entrepreneur with the same financial wealth and no legacy capital. However, unobserved by his bank, the crook will not open a shop (we can assume that crooks do not even know how to open a shop). Instead, he deposits the loan in his bank account and never repays any amount of the loan. The following week, the bank will realize that he is a crook, but we assume that there is nothing the bank can do at this stage other than write the loan down to zero in its books.

We also assume that crooks can never become bank owners. Given that crooks and other non-bank-owning, non-shop-owning people have the same probability of becoming an entrepreneur, the fraction of loan applications coming from crooks will be $p^{c}=\frac{N^{c} n}{N-\Omega-5}$, where $\Omega$ is the number of shops at the start of the week, assumed to be known by all banks. We further assume that a new bank (i.e., one that has been in business for less than $T^{c}$ weeks) sets a loan rate $i_{L}$ such that its expected return from a new loan is equal to $i_{w}+s / 48$, the loan rate of an experienced bank; since the bank loses interest plus principal from each loan to a crook, this means that

$$
i_{L}=\frac{1+i_{w}+s / 48}{1-p^{c}}-1
$$

At the beginning of the goods and labor market trading stage of each week, we assume that, for each legitimate shop owner that applies for a loan to finance a firesale purchase, there is a probability $\frac{p^{c}}{1-p^{c}}$ that a crook will apply for a loan of the same size. Again, the new bank cannot tell these fraudulent loan applications from legitimate ones, although it knows that the fraction $p^{c}$ of such loans are being granted to crooks. We set the initiation period $T^{c}$ of a new bank equal to 48 weeks. Once the initiation period is over, the bank simply rejects all loan applications coming from crooks.

In this variation of the model, the presence of crooks can make bank failure a problem since now there will be a very high interest rate to be paid by new entrants and by established firms in 20 percent of the economy for a year following the exit of a bank. This could potentially reverse our ranking of safe and risky banks, in terms of worst-decile macro performance, since risky banks fail more often than safe banks. 
TABLE 5: Worst-decile average outcomes with "crooks" in the model

\begin{tabular}{lccc}
\hline Variable & Banks & No banks & Risky banks \\
\hline Inflation & 2.6 & 1.4 & 2.8 \\
Output gap & 13 & 44 & 11 \\
Unemployment rate & 11 & 28 & 8.8 \\
Unemployment duration & 17 & 27 & 13 \\
Job loss rate & 0.66 & 1.9 & 0.7 \\
Volatility of output gap & 6.8 & 23 & 5.0 \\
Volatility of inflation & 1.1 & 1.8 & 0.85 \\
Annual bank failure rate & 2.2 & 0 & 3.8 \\
Fraction of banks in trouble & 18 & 0 & 2.4 \\
\hline
\end{tabular}

Our results, however, indicate that it takes a lot of crooks in order for this ranking to be reversed. Table 5 shows the results for worst-decile average performance, under the safe and risky scenarios, from simulating this variant of our model with 4 crooks in each market. As is evident from a comparison with Table 4, under both the safe and risky scenarios, the economy's worstdecile average performance is worse by almost all measures than it was without crooks. In this case, since the number of shops $\Omega$ at the start of each week is usually about 60 , the fraction $p^{c}$ of loans coming from crooks is more than 8.5 percent, meaning that the (per annum) loan rate of a new bank, instead of being about 5 percent, is almost 15 percent. Nevertheless, it appears that macro performance is better under the risky scenario, which involves much more bank failure than does the safe scenario. Indeed, we found that the number of crooks had to be raised to 6 per market in order to make the economy's worst-decile results better with safe than with risky banks, at which point the new bank's loan rate is about 20 percent per annum!

\section{Sensitivity analysis}

In this section, we subject our main findings to a sensitivity analysis. In particular, we perturbed each of the model's 33 parameters in turn, first setting it higher than the baseline value indicated in Table 1 and then setting it lower, and recorded the median value of the 40-year average output gap across 10,000 simulation runs. For all but two parameters, the perturbation was either plus or minus 25 percent of the baseline value. One exception was the size of price change $\delta_{p}$, in which case we perturbed $\delta_{p}-1$ by plus or minus 25 percent. The other exception was the number of banks $m$, which needs to be a divisor of the number of goods 50 to preserve the symmetry of the model's setup across sectors; in this case, we set the perturbed values of $m$ at the nearest divisors of 50 , namely $m=10$ and $m=2$.

Figure 15 shows the effects of varying each parameter on the median output gap. ${ }^{29}$ There are three parameters that can raise the output gap (i.e., reduce output) by more than 1 percentage

\footnotetext{
${ }^{29}$ The results from sensitivity analyses conducted on the median values of the other eight indicators listed in Table 4 are qualitatively similar, and are available from the authors upon request.
} 


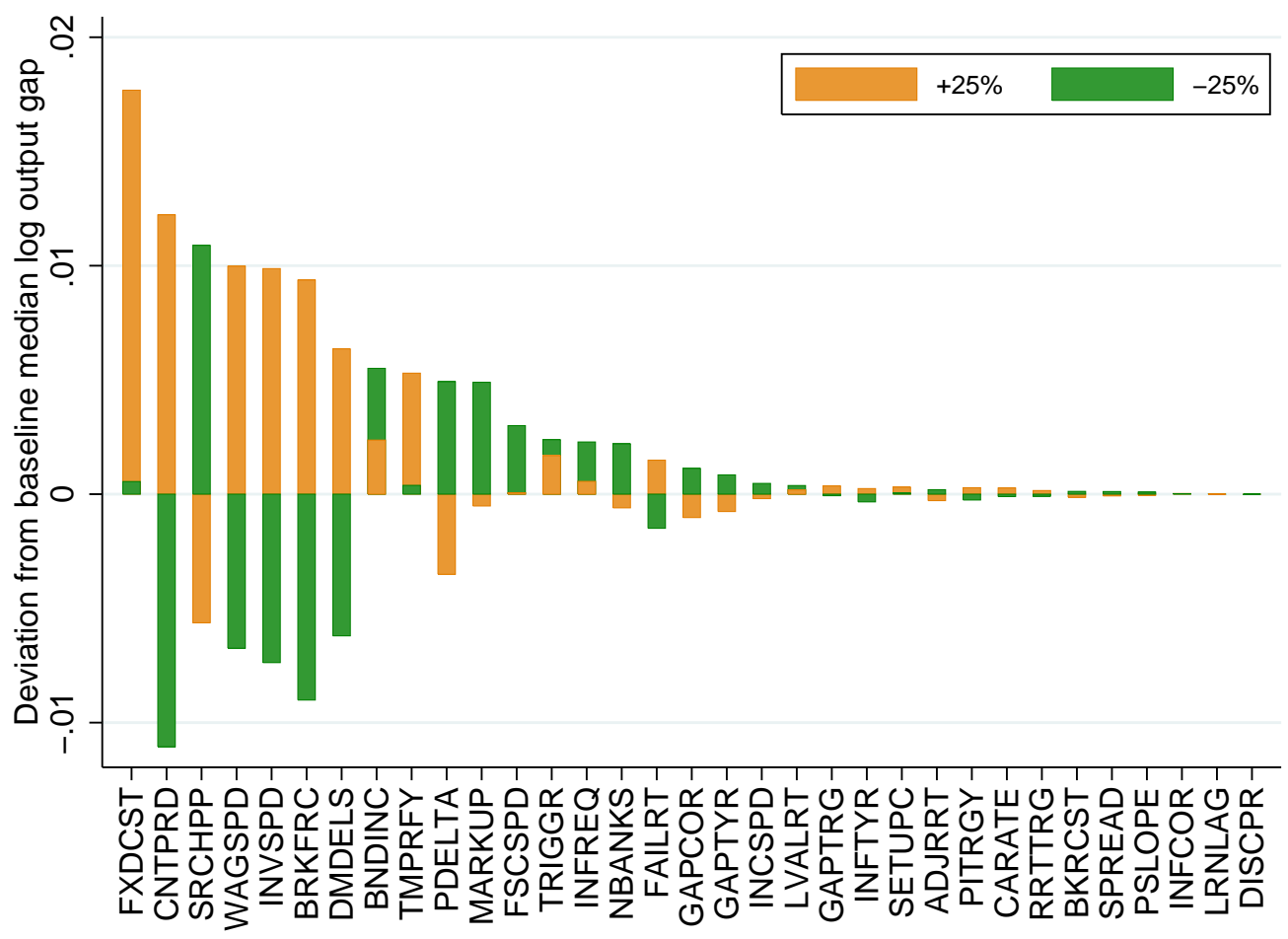

FIGURE 15: Effect on median output gap from perturbing each parameter

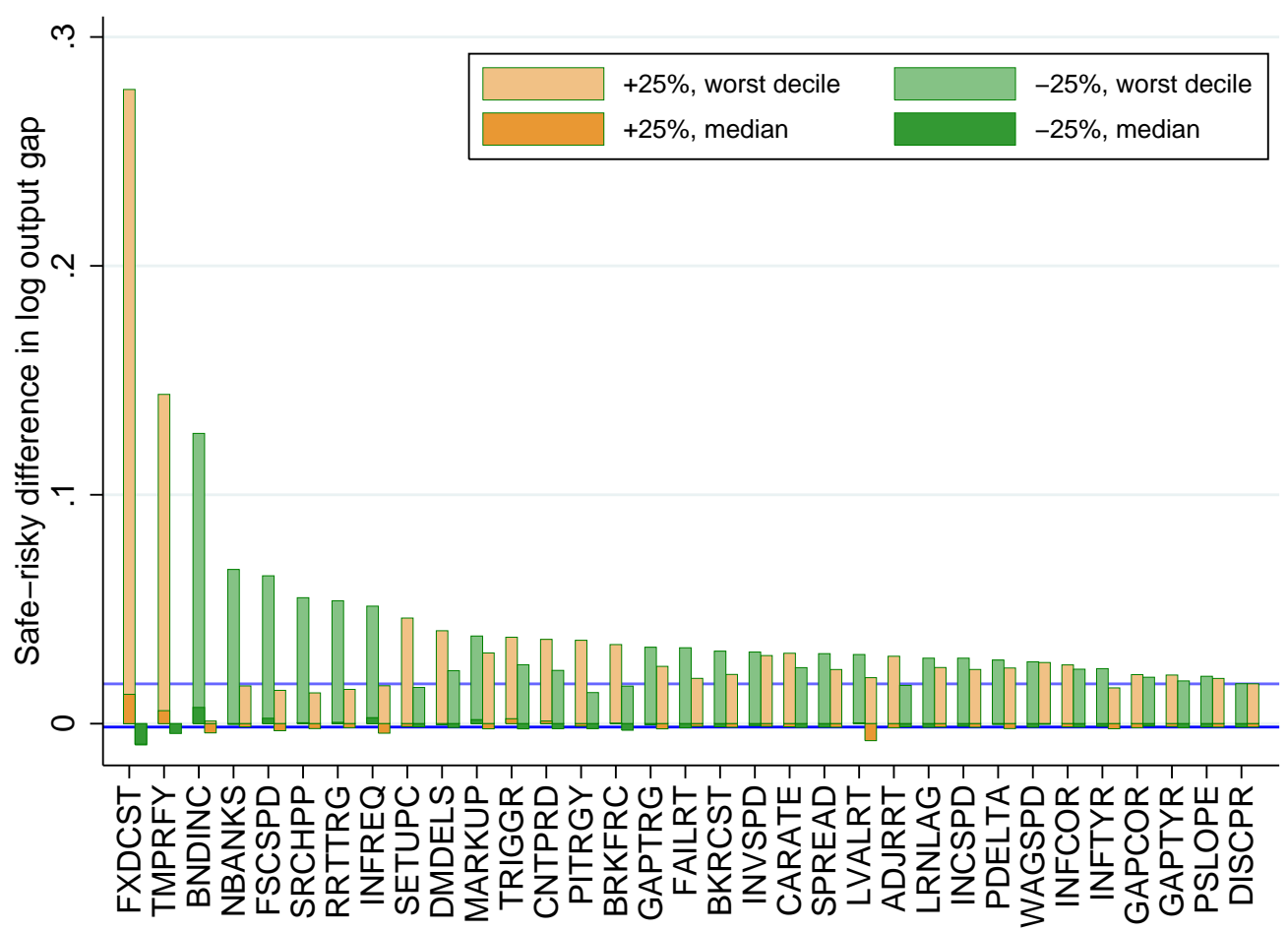

FiguRE 16: Effect on safe-risky output gap difference from perturbing each parameter 
point, namely the fixed cost $F$, the length of the wage contract period $\Delta$, and the job search propensity $\sigma$. Of these, the fixed cost is the most important. When it rises, firms are less likely to enter and more likely to fail, resulting in a lower number of shops on average and, thus, a greater degree of market disorganization.

More than half the parameters appear to have little effect on median performance. As shown in Figure 15, 18 of the 33 parameters have an effect of less than or equal to one-tenth of a percentage point on median output when varied \pm 25 percent. These parameters include all the initialization values used by the central bank, namely its initial estimates for log potential GDP $\tilde{y}_{0}$ and the autoregressive coefficient $\lambda_{y 0}$ in its forecast equation for $\log$ GDP, its initial estimate for the autoregressive coefficient $\lambda_{\pi 0}$ in its forecast equation for inflation, and its initial real interest rate target $r_{0}^{*}$. They also include technical parameters such as the adjustment speed $\eta_{r}$ in the central bank's real interest rate target revisions and the length $T_{\mathrm{cb}}$ of its learning period. However, there are also another 12 parameters whose values we thought would matter but that seem to have little effect on median performance. These parameters include the inflation target $\pi^{*}$, the other two Taylor-rule parameters $\gamma_{y}$ and $\gamma_{\pi}$, and other policy parameters such as the loan-to-value ratio $h$, the capital adequacy ratio $\kappa$, and the Fed's discount rate premium $s_{d}$. Several private sector parameters are also relatively unimportant by the same criterion, namely the speed of adjustment $\lambda_{p}$ of permanent income, the setup cost $S$, the foreclosure cost parameter $C_{b}$, the annual loan spread $s$, and the slope $l$ of each bank's loan approval schedule.

Despite the fact that several parameters have a quantitatively significant effect on median performance, Figure 16 shows that our result to the effect that risky banks yield superior macro performance as compared with safe banks, especially in worst-case scenarios, is qualitatively robust to 25 percent perturbations in almost all parameters. Specifically, the blue line in this figure shows the safe-risky difference in the worst-decile average output gap in our baseline calibration, which is 0.017. The lightly shaded bars indicate the same difference under parameter perturbations, orange denoting +25 percent and green denoting -25 percent. All but 2 of these 66 bars indicate a positive difference, as in our baseline calibration, and neither of the 2 exceptions yielded a difference larger than 0.01 in absolute value. The parameter whose perturbations had the most effect on this

difference was again the fixed cost $F$, which yielded a safe-risky difference of 0.277 when it was increased by 25 percent.

\section{Conclusion}

In this paper, we developed an agent-based computational macro model, focusing on the mechanism that normally makes a free-market economic system self-organizing and self-regulating - its network of specialist trading enterprises. We applied our model to explore the role that the banking system plays in this mechanism. 
Our investigation generates a number of interesting results. Specifically, our analysis suggests that banks can improve an economy's performance by facilitating the entry of shops that organize economic transactions, and that this improvement is most noticeable in worst-case scenarios. In this respect, banks in our model provide a financial stabilizer that more than counteracts the more familiar financial accelerator. Our analysis thus sheds new light on the conflict between microprudential bank regulation and macroeconomic stability - while bank regulation in normal times makes little difference for macro performance, in bad times the economy performs significantly worse under more stringent regulation because it suppresses the lending activity that is especially needed in such times. We conclude by reiterating the exploratory nature of our present investigation, but emphasize its methodological contribution in providing a framework that yields insights that might be elusive in more conventional frameworks for analyzing the role of the banking system in a macroeconomy. 


\section{References}

Aghion, Philippe, and Peter Howitt. The Economics of Growth. Cambridge, MA: MIT Press, 2009.

Amano, Robert, Kevin Moran, Stephen Murchison, and Andrew Rennison. "Trend Inflation, Wage and Price Rigidities, and Productivity Growth." Journal of Monetary Economics 56 (April 2009): $353-364$.

Ashraf, Quamrul, and Peter Howitt. "How Inflation Affects Macroeconomic Performance: An Agent-Based Computational Investigation.” Unpublished, Brown University, 2008.

Barro, Robert J., and Herschel I. Grossman. Money, Employment, and Inflation. New York: Cambridge University Press, 1976.

Basu, N., R. Pryor, and T. Quint. "ASPEN: A Microsimulation Model of the Economy." Computational Economics 12 (December 1998): 223-241.

Bennet, Robert L., and Barbara R. Bergmann. A Microsimulated Transactions Model of the United States Economy. Baltimore: The Johns Hopkins University Press, 1986.

Bernanke, Ben, and Mark Gertler. "Agency Costs, Net Worth, and Business Fluctuations." American Economic Review 79 (March 1989): 14-31.

Bils, Mark, and Peter J. Klenow. "Some Evidence on the Importance of Sticky Prices." Journal of Political Economy 112 (October 2004): 947-985.

Blanchard, Olivier, and Jordi Gali. "Labor Markets and Monetary Policy: A New Keynesian Model with Unemployment." American Economic Journal: Macroeconomics 2 (April 2010): 1-30.

Bohn, Henning. "The Behavior of U.S. Public Debt and Deficits." Quarterly Journal of Economics 113 (August 1998): 949-963.

Braun, Matías, and Borja Larrain. "Finance and the Business Cycle: International, Inter-Industry Evidence." Journal of Finance 60 (June 2005): 1097-1128.

Bris, Arturo, Ivo Welch, and Ning Zhu. "The Costs of Bankruptcy: Chapter 7 Liquidation versus Chapter 11 Reorganization." Journal of Finance 61 (June 2006): 1253-1303.

Burstein, Ariel, and Christian Hellwig. "Welfare Costs of Inflation in a Menu Cost Model." American Economic Review: Papers and Proceedings 98 (May 2008): 438-443.

Cincotti, Silvano, Marco Raberto, and Andrea Teglio. "Credit Money and Macroeconomic Instability in the Agent-based Model and Simulator Eurace." Economics: The Open-Access, OpenAssessment E-Journal 4 (September 2010).

Clower, Robert. "The Keynesian Counter-revolution: A Theoretical Appraisal." In The Theory of Interest Rates, edited by Frank Hahn and Frank Brechling, 103-125. London: Macmillan, 1965. 
Deissenberg, Christophe, Sander van der Hoog, and Herbert Dawid. "EURACE: A Massively Parallel Agent-Based Model of the European Economy." Applied Mathematics and Computation 204 (October 2008): 541-552.

Delli Gatti, Domenico, Edoardo Gaffeo, Mauro Gallegati, Gianfranco Giulioni, and Antonio Palestrini. Emergent Macroeconomics: An Agent-Based Approach to Business Fluctuations. New York: Springer, 2008.

Dosi, Giovanni, Giorgio Fagiolo, and Andrea Roventini. "An Evolutionary Model of Endogenous Business Cycles." Computational Economics 27 (February 2006): 3-34.

Dunne, Timothy, Mark J. Roberts, and Larry Samuelson. "Patterns of Firm Entry and Exit in U.S. Manufacturing Industries." RAND Journal of Economics 19 (Winter 1988): 495-515.

Durlauf, Steven N., and Louis J. Maccini. "Measuring Noise in Inventory Models." Journal of Monetary Economics 36 (December 1995): 65-89.

Easterly, William, Roumeen Islam, and Joseph E. Stiglitz. "Shaken and Stirred: Explaining Growth Volatility." In Annual World Bank Conference on Development Economics 2000, edited by Boris Pleskovic and Nicholas Stern, 191-211. Washington: World Bank Publications, 2000.

Eggertsson, Gauti B., and Michael Woodford. "The Zero Bound on Interest Rates and Optimal Monetary Policy." Brookings Papers on Economic Activity 34 (2003-1): 139-235.

Eliasson, Gunnar. "Competition and Market Processes in a Simulation Model of the Swedish Economy." American Economic Review: Papers and Proceedings 67 (February 1977): 277-281.

Gertler, Mark, and Nobuhiro Kiyotaki. "Financial Intermediation and Credit Policy in Business Cycle Analysis." In Handbook of Monetary Economics, edited by Benjamin M. Friedman and Michael Woodford, 547-599. Amsterdam: North Holland, 2010.

Gertler, Mark, Luca Sala, and Antonella Trigari. "An Estimated Monetary DSGE Model with Unemployment and Staggered Nominal Wage Bargaining." Journal of Money, Credit, and Banking 40 (December 2008): 1713-1764.

Golosov, Mikhail, and Robert E. Lucas Jr. "Menu Costs and Phillips Curves." Journal of Political Economy 115 (April 2007): 171-199.

Hall, Robert E. "Lost Jobs." Brookings Papers on Economic Activity 26 (1995-1): 221-274.

Holmstrom, Bengt, and Jean Tirole. "Financial Intermediation, Loanable Funds, and the Real Sector." Quarterly Journal of Economics 112 (August 1997): 663-691.

Howitt, Peter. "The Microfoundations of the Keynesian Multiplier Process." Journal of Economic Interaction and Coordination 1 (May 2006): 33-44.

Howitt, Peter. "Macroeconomics with Intelligent Autonomous Agents." In Macroeconomics in the Small and the Large: Essays on Microfoundations, Macroeconomic Applications and Economic 
History in Honor of Axel Leijonhufvud, edited by Roger E. A. Farmer, 157-177. Cheltenham, UK: Elgar, 2008.

Howitt, Peter, and Robert Clower. "The Emergence of Economic Organization." Journal of Economic Behavior and Organization 41 (January 2000): 55-84.

Kiyotaki, Nobuhiro, and John Moore. "Credit Cycles." Journal of Political Economy 105 (April 1997): 211-248.

Leijonhufvud, Axel. "Effective Demand Failures." Swedish Journal of Economics 75 (March 1973): $27-48$.

Leijonhufvud, Axel. "Towards a Not-Too-Rational Macroeconomics." Southern Economic Journal 60 (July 1993): 1-13.

Leijonhufvud, Axel. "Agent-Based Macro." In Handbook of Computational Economics, edited by Leigh Tesfatsion and Kenneth L. Judd, 1625-1637. Vol. 2. Amsterdam: North-Holland, 2006.

Levin, A., D. López-Salido, E. Nelson, and T. Yun. "Limitations on the Effectiveness of Forward Guidance at the Zero Lower Bound." International Journal of Central Banking 6 (March 2010): 143-189.

Levine, Ross. "Finance and Growth: Theory and Evidence." In Handbook of Economic Growth, edited by Philippe Aghion and Steven N. Durlauf, 865-934. Vol. 1. Amsterdam: Elsevier, 2005.

Loayza, Norman, and Claudio Raddatz. "The Structural Determinants of External Vulnerability." World Bank Economic Review 21 (October 2007): 359-387.

Midrigan, Virgiliu. "Menu Costs, Multi-Product Firms, and Aggregate Fluctuations." Econometrica, 2011, forthcoming.

Nakamura, Emi, and Jón Steinsson. "Monetary Non-Neutrality in a Multi-Sector Menu Cost Model." Quarterly Journal of Economics 125 (August 2010): 961-1013.

Orcutt, Guy, Steven Caldwell, and Richard Wertheimer II. Policy Exploration through Microanalytic Simulation. Washington: The Urban Institute, 1976.

Patinkin, Don. Money, Interest, and Prices. 1st ed. New York: Row Peterson, 1956; 2nd ed. New York: Harper and Row, 1965.

Phelps, Edmund S., and Sydney G. Winter Jr. "Optimal Price Policy Under Atomistic Competition." In Microeconomic Foundations of Employment and Inflation Theory, edited by Edmund S. Phelps et al. New York: Norton, 1970.

Raddatz, Claudio. "Liquidity Needs and Vulnerability to Financial Underdevelopment." Journal of Financial Economics 80 (June 2006): 677-722.

Roberts, John M. "New Keynesian Economics and the Phillips Curve." Journal of Money, Credit and Banking 27 (November 1995): 975-984. 
Smets, Frank, and Rafael Wouters. "Shocks and Frictions in U.S. Business Cycles: A Bayesian DSGE Approach." American Economic Review 97 (June 2007): 586-606.

Stigler, George. "The Economics of Information." Journal of Political Economy 69 (June 1961): $213-225$.

Tesfatsion, Leigh. "Agent-Based Computational Economics: A Constructive Approach to Economic Theory." In Handbook of Computational Economics, edited by Leigh Tesfatsion and Kenneth L. Judd, 831-880. Vol. 2. Amsterdam: North-Holland, 2006.

Tesfatsion, Leigh, and Kenneth L. Judd, eds. Handbook of Computational Economics. Vol. 2. Amsterdam: North-Holland, 2006.

Wallis, John J., and Douglass C. North. "Measuring the Transaction Sector in the American Economy, 1870-1970." In Long Term Factors in American Economic Growth, edited by S. L. Engerman and R. E. Gallman, 95-162. Chicago: University of Chicago Press, 1986.

Williamson, Stephen D. "Financial Intermediation, Business Failures, and Real Business Cycles." Journal of Political Economy 95 (December 1987): 1196-1216.

Woodford, Michael. Interest and Prices: Foundations of a Theory of Monetary Policy. Princeton, NJ: Princeton University Press, 2003. 